\title{
Enhanced Gas-Liquid Mass Transfer of an Oscillatory Constricted-Tubular Reactor
}

\author{
Nuno Reis, ${ }^{\dagger}$ Ricardo N. Pereira, António A. Vicente,* and José A. Teixeira \\ IBB-Institute for Biotechnology and Bioengineering, Center of Biological Engineering, Universidade do \\ Minho, Campus de Gualtar, 4710-057 Braga, Portugal
}

The mass transfer performance has been tested for gas-liquid flow in a new tubular reactor system, the oscillating mesotube (OMT), which features the oscillatory movement of fluid across a series of smooth constrictions located periodically along the vertical $4.4 \mathrm{~mm}$ internal diameter tube. The effect of the fluid oscillations (frequency, $f$, and center-to-peak amplitude, $x_{0}$, in the range of $0-20 \mathrm{~s}^{-1}$ and $0-3 \mathrm{~mm}$, respectively) on the overall volumetric mass transfer coefficient $\left(k_{\mathrm{L}} a\right)$ has been tested by measuring the oxygen saturation levels with a fiber-optical microprobe (oxygen micro-optrode), and a mathematical model has been produced to describe the oxygen mass transport in the OMT. The oxygen mass transfer rates were about 1 order of magnitude higher $\left(k_{\mathrm{L}} a\right.$ values up to $\left.0.16 \mathrm{~s}^{-1}\right)$ than those values reported for gas-liquid contacting in a 50 $\mathrm{mm}$ internal diameter oscillatory flow reactor (OFR), for the same peak fluid oscillatory velocity, i.e., $2 \pi f x_{0}$. This represents remarkable oxygen transfer efficiencies, especially when considering the very low mean superficial gas velocity involved in this work $\left(0.37 \mathrm{~mm} \mathrm{~s}^{-1}\right)$. The narrower constrictions helped to increase the gas fraction (holdup) by reducing the rise velocity of the bubbles. However, the extent of radial mixing and the detachment of vortex rings from the surface of the periodic constrictions are actually the main causes of bubbles retention and effective gas-liquid contacting and are, thus, responsible for the enhancement of $k_{\mathrm{L}} a$ in the OMT.

\section{Introduction}

Gas-liquid flow is widely used in chemical and biochemical engineering, including gas-liquid catalytic reactions, fermentations, and photosynthesis by micro-organisms. The gas-liquid oxygen mass transfer coefficient $\left(k_{\mathrm{L}} a\right)$ is an important parameter when considering the application of a gas-liquid contacting technology in oxygen-dependent processes (e.g., many biological transformations) and has been studied for decades in conventional gas-liquid contacting systems, e.g., stirred tank reactors (STRs), bubble columns (BCs), or air-lift reactors (ALRs). Nowadays, both chemical and biochemical engineers are being attracted by the unique advantages presented by the scale-down platforms as an alternative to the conventional scaled-up systems. This change is being driven by demands in sustainability and production objectives and is powering the Process Intensification of industrial processes. However, gas-liquid contacting in small-scale platforms is particularly challenging because of reduced mixing intensities and contacting times commonly found in such systems.

Fluid oscillations in the presence of periodic constrictions are an outstanding method for enhancing the mass transfer rates in heterogeneous systems. The recent development of a new oscillatory flow screening mesoreactor ${ }^{1}$ has been an important milestone in the scale-down of baffled, oscillatory flow reactors (OFRs). The internal diameter of the tube has been scaled-down by 1 order of magnitude (i.e., from 50 to $\sim 5 \mathrm{~mm}$ ), and the geometry of the periodic constrictions has been adjusted to be smooth rather than sharp, making it compatible with the design's requirements of bioprocessing and fine chemicals industries. These features have turned the oscillatory mesotube (OMT) into

* To whom correspondence should be addressed. E-mail: avicente@deb.uminho.pt.

Current address: University of Cambridge, Department of Chemical Engineering, New Museums Site, Cambridge CB2 3RA, United Kingdom. a potential screening unit for bioprocess development as published by Reis et al. ${ }^{2}$ Previous studies have suggested exploring the OMT as a gas-liquid contacting technology, thus establishing the purpose of this present work. Because of its particular geometry (a tubular system with a small internal diameter), the experimental determination of oxygen transfer rates in the OMT is challenging and the standard methods for $k_{\mathrm{L}} a$ evaluation cannot be directly implemented, as will be discussed.

Results of $k_{\mathrm{L}} a$ measurement were extensively reported for many devices, from high-power rotary agitators to bubble columns, for many processes and using different methods. The principal methods for estimating the $k_{\mathrm{L}} a$ may be classified in five main groups: (a) dynamic methods (e.g., dynamic oxygen electrode and start-up methods); (b) steady-state sulfite method; (c) dynamic pressure method (DPM); (d) peroxide methods; and (e) response methods. A survey of the main methods employed at the industrial scale is presented by Gogate and Pandit. ${ }^{3}$ Reported works cover a wide range of reactor types. ${ }^{4-9}$

The improvement of gas-liquid mass transfer in baffled tubes in the presence of fluid oscillations ${ }^{10}$ has faced little attention until the 1990 s, with a few exceptions. ${ }^{5,6,11}$ The recent growing interest in OFRs led to the achievement of important results concerning mass transfer in this type of reactor. Oxygen mass transfer for an air-water system in an OFR was reported by Hewgill et al.; ${ }^{12}$ a 6 -fold increase in $k_{\mathrm{L}} a$ was obtained in comparison with a $\mathrm{BC}$. $\mathrm{Ni}$ et al. ${ }^{13}$ also reported $75 \%$ higher values of $k_{\mathrm{L}} a$ with an OFR when compared to a STR at similar power inputs. The first explanation for this effect was an increase in the gas holdup (and, hence, in the specific surface, $a$ ), in accordance to Serieys et al. ${ }^{9}$ and Baird and Gargstang. ${ }^{5}$ An alternative explanation for such $k_{\mathrm{L}} a$ improvements in OFRs was later introduced by $\mathrm{Ni}$ et al.: ${ }^{13}$ the more even distribution of the shear rates in the OFR leads to thinner liquid films, hence increasing the mass transfer term, $k_{\mathrm{L}}$. 
A recent work by Ellenberger and Krushna ${ }^{14}$ at the University of Amsterdam has shown that the application of low-frequency vibrations in a plain, vertical bubble column has the great potential of improving the gas-liquid mass contacting. The vibrations were observed to cause smaller bubbles being generated in the nozzle with significant enhancements in the gas holdup and $k_{\mathrm{L}} a$ by a factor of 2 or more, which was associated with the levitation of bubbles in the column.

Few methods for estimating $k_{\mathrm{L}} a$ have been explored in OFRs. Hewgill et al. ${ }^{12}$ considered the dynamic nitrogen purge method as an accurate method for $k_{\mathrm{L}} a$ measurement in a batch OFR. The same technique is also recommended by Linek et al. ${ }^{15}$ Although being the one most used in laboratories, this method leads in some circumstances to wrong values of $k_{\mathrm{L}} a$, as pointed out by Hewgill et al. ${ }^{12} \mathrm{Ni}$ et al., ${ }^{16}$ for example, used the dynamic gassing-out technique in a $50 \mathrm{~mm}$ internal diameter OFR; however, the same author has identified a pitfall of the gassingout method in a subsequent work: a well-mixed state needs to be achieved within a reactor if this method is to be used for $k_{\mathrm{L}} a$ determination in a batch OFR. ${ }^{17}$

Oxygen electrodes (the most widely sensors applied to the measurement of dissolved oxygen, DO) can limit the accuracy of $k_{\mathrm{L}} a$ measurement. van't Riet ${ }^{18}$ concluded that the use of commercially available probes enables the measuring of $k_{\mathrm{L}} a$ up to $0.1 \mathrm{~s}^{-1}$ with little losses of accuracy and without the need to use response models if the response time of the probe is $2-3$ s. However, for most commercial DO probes, this is not the case, with the compensation of the different time responses of the probes being essential even when this is as small as $3 \mathrm{~s} .{ }^{16,17}$

In comparison with DO electrodes, the oxygen optrodes (the optical equivalent of electrodes) seem more suitable for bioengineering applications. First, sensing does not consume oxygen; second (and as a consequence of that), the partial pressure of oxygen in the optrode's tip (where a fluorescent dye is located) is in equilibrium with the partial pressure outside the optrode. As the optrode response is directly related to oxygen concentration (and not to the oxygen flow), the modification of the diffusion properties of the optrode would have any effect just on altering its response time. Furthermore, optrodes offer many advantages due to the utilization of fiber-optical technology, such as remote sensing, small size, and sensor networking. ${ }^{19}$

It is generally accepted that the straight application of the major methods for measurement of $k_{\mathrm{L}} a$ values (essentially the dynamic and the response ones) is reduced to the situation of perfect mixing in the liquid phase. ${ }^{3}$ That is not the situation for most of the "real" reactors. In this study, the DO saturation levels were monitored in the continuous OMT with a micro-optrode and the $k_{\mathrm{L}} a$ values were estimated through mathematical modeling of the oxygen mass transport at different combinations of fluid oscillation frequency $(f)$ and center-to-peak amplitude $\left(x_{0}\right)$ in the ranges $0-20 \mathrm{~s}^{-1}$ and $0-3 \mathrm{~mm}$, respectively.

\section{Experimental Apparatus and Procedures}

2.1. Oscillatory Mesotube. The OMT consists of a jacketed, glass tube provided with smooth periodic constrictions. The maximum internal diameter $(d)$ is equal to $4.4 \mathrm{~mm}$, and the ratio of constriction-free cross section to the maximum free cross section is $\sim 13 \%$. Two lengths for OMT were tested in this work: (a) OMT1 with $350 \mathrm{~mm}$ and (b) OMT2 with $75 \mathrm{~mm}$, as shown in Figure 1 and further detailed in Table 1. Fluid oscillations were produced using a rotating ceramic piston pump (CKCRHO, Fluid Metering Inc., New York) working in closed loop. The design of such a pump (valveless rotating and reciprocating piston) allowed for obtaining good sinusoidal oscillations in the

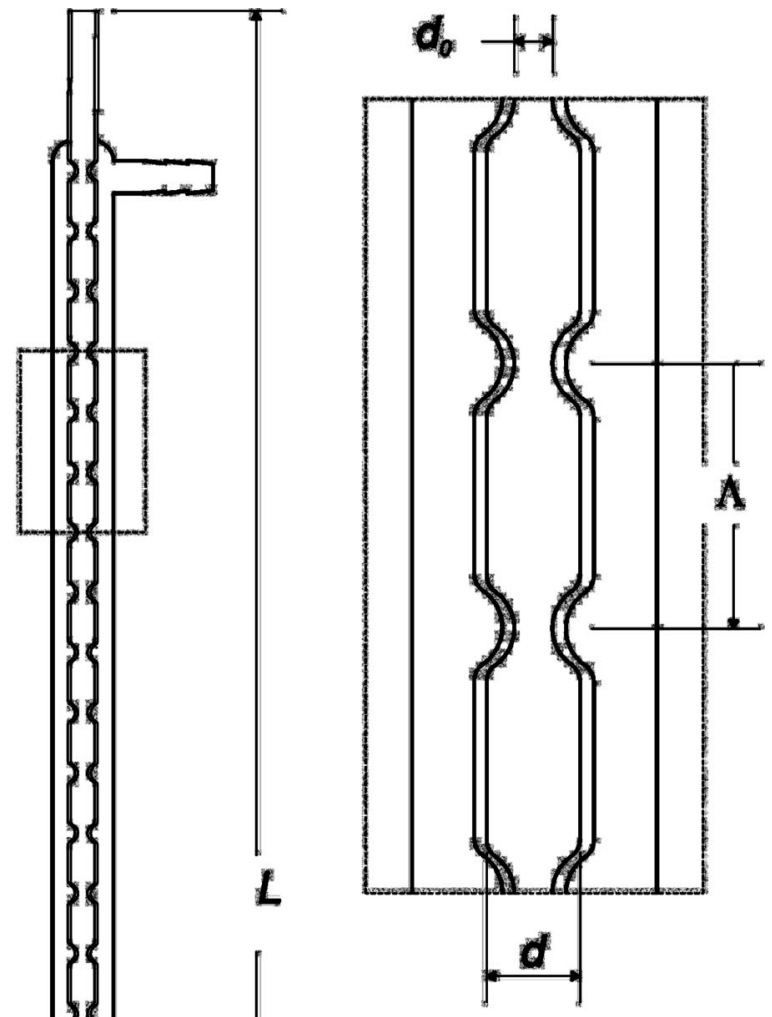

(a)

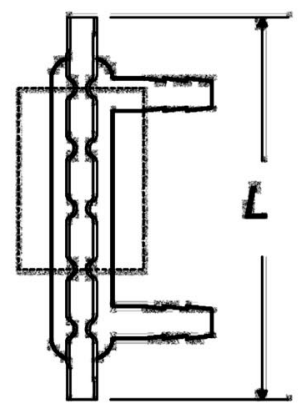

(b)

(c)

Figure 1. Geometry of the OMT, detailing the (a) tube's geometry, (b) design of a $350 \mathrm{~mm}$ length (OMT1), and (c) design of a $75 \mathrm{~mm}$ length (OMT2). $\Lambda$ is the distance between two consecutive constrictions; $d$ is the internal tube diameter; $d_{0}$ is the constriction-free diameter; and $L$ is the length of the tube.

fluid. The value of $x_{0}$ was well-controlled by turning the flowcontrol ring in the pump's head. The relationship between the piston position $\left(h_{\mathrm{p}}\right)$ and $x_{0}$ (calculated in the maximum internal tube diameter, i.e., $d=4.4 \mathrm{~mm}$ ) is given by the following relation: $x_{0}(\mathrm{~mm})=7.3074 \times 10^{-3} \cdot h_{\mathrm{p}}$. The angular velocity of the motor gives a direct control over $f$. In all, a precise and independent control of both $x_{0}$ and $f$ is obtained with this setup.

The intensity of mixing in the OMT can be described by the oscillatory Reynolds number, $R e_{\mathrm{o}}$, defined as follows: ${ }^{12}$ 


$$
R e_{\mathrm{o}}=\frac{2 \pi f x_{0} \rho d}{\mu}
$$

The formation and dissipation of eddies in an OFR results in significant enhancements of mass-transfer processes. ${ }^{12}$ In particular, the OFR's geometry has been demonstrated to increase the holdup of bubbles and particles and is an effective method of controlling liquid droplet and bubble size distributions. ${ }^{20,21}$

2.2. Experimental Setup. An OMT was fixed vertically and mounted as illustrated in Figure 2. A constant, continuous liquid flow rate $\left(Q_{\mathrm{L}}\right)$ of $1.58 \mathrm{~mL} \mathrm{~min}^{-1}$ was pumped with a peristaltic pump through a reservoir and connected downstream of the closed-oscillation loop, thus avoiding losing the fluid pulsations. Distilled water was used as the liquid phase and was deaerated using nitrogen gas. A constant airflow rate $\left(Q_{\mathrm{G}}\right)$ of $0.28 \mathrm{~mL}$ $\min ^{-1}$ (corresponding to a mean superficial gas velocity, $v_{\mathrm{SG}}$, of $0.37 \mathrm{~mm} \mathrm{~s}^{-1}$ ) was sparged through a syringe needle in the bottom of the OMT, and DO concentration at the top of the OMT (represented as oxygen saturation, $x_{\mathrm{O}_{2}}{ }{ }^{\text {ut }}$ ) was monitored until a steady response was attained. No other gas distribution method was tried because the mass transfer under oscillatory flow is dominated by the fluid flow patterns and is independent of the gas distributor, as concluded by Oliveira and $\mathrm{Ni}^{21}$ The typical time to achieve the steady response in DO concentration was about $10-15$ hydraulic residence times, i.e., $\sim 30-45 \mathrm{~min}$.

2.3. Measurement of DO Saturation Levels. The values of $x_{\mathrm{O}_{2}}{ }^{\text {out }}$ were continuously measured with a calibrated, fiberoptic fluorescence microprobe (oxygen micro-optrode) provided with SMA connectors (Avs-oxyprobe-1.5, Avantes, Eerbeek, The Netherlands). The working tip of the micro-optrode (1.5 $\mathrm{mm}$ diameter) was dip-coated with a ruthenium complex immobilized in a sol-gel matrix. When this complex is excited to fluorescence by a blue LED ( $475 \mathrm{~nm}$ output peak), the level of the fluorescence (at about $600 \mathrm{~nm}$ ) is inversely related to $x_{\mathrm{O}_{2}}{ }^{\text {out }}$ according to the Stern-Volmer equation, ${ }^{19,22}$

$$
\frac{I_{0}}{I}=1+K_{\mathrm{Sv}} x_{\mathrm{O}_{2}}{ }^{\text {out }}
$$

where $I_{0}$ and $I$ are the fluorescence intensities in the absence and presence of oxygen, respectively; $K_{\mathrm{SV}}$ is the Stern-Volmer constant; and $x_{\mathrm{O}_{2}}{ }^{\text {out }}$ is the oxygen saturation. ${ }^{19}$

The level of fluorescence in the micro-optrode was measured with an optical spectrometer (AvaLights-2048, Avantes, Eerbeek, The Netherlands). The 2048 pixels charge-coupled device (CCD) detector was connected to an electronic board with a 14 bit AD converter and USB/RS-232 interface. Data transfer between the optic spectrometer and a personal computer was controlled by AvaSoft full software (Avantes, Eerbeek, The Netherlands).

Table 1. Specifications of the OMT1 and OMT2

\begin{tabular}{lcc}
\hline & OMT1 & OMT2 \\
\hline tube length $(L), \mathrm{mm}$ & 350 & 75 \\
gas-sparger to micro-optrode distance $\left(L^{\prime}\right), \mathrm{mm}$ & 346 & 100 \\
internal volume, mL & $\sim 4.4$ & $\sim 1.0$ \\
maximum internal diameter $(d), \mathrm{mm}$ & 4.4 \\
mean cross-sectional average internal diameter, mm & 4.0 \\
constriction-free diameter $\left(d_{0}\right), \mathrm{mm}$ & \multicolumn{2}{c}{1.6} \\
interconstrictions distance $(\Lambda), \mathrm{mm}$ & 13 \\
fluid oscillation frequency $(f), \mathrm{s}^{-1}$ & $0-20$ \\
fluid oscillation center-to-peak amplitude $\left(x_{0}\right), \mathrm{mm}$ & $0-3.0$ \\
volumetric liquid flow rate $\left(Q_{\mathrm{L}}\right), \mathrm{mL} \mathrm{min}^{-1}$ & \multicolumn{2}{c}{1.58} \\
volumetric gas flow rate $\left(Q_{\mathrm{G}}\right), \mathrm{mL} \mathrm{min}^{-1}$ & 0.28 \\
mean superficial fluid velocity $\left(v_{\mathrm{L}}\right)^{a}, \mathrm{~mm} \mathrm{~s}^{-1}$ & 2.1 \\
mean superficial gas velocity $\left(v_{\mathrm{SG}}\right)^{a}, \mathrm{~mm} \mathrm{~s}^{-1}$ & 0.37
\end{tabular}

${ }^{a}$ On the basis of a mean internal diameter equal to $4.0 \mathrm{~mm}$.
The micro-optrode was attached to a flow cell installed at the top of the OMT and spaced from the point of gas sparging by a distance $L^{\prime}$ described in Table 1 . As for certain fluid oscillation conditions, the diameter of the micro-optrode is of the same magnitude of the bubbles' diameter; the problem of direct impingement of bubbles in the micro-optrode was minimized using a plain pipe section in the flow cell (Figure 2) with an internal diameter slightly larger $(5.0 \mathrm{~mm})$ than $d$ (Figure 2). This arrangement avoided the attachment of bubbles to the micro-optrode tip, which might complicate the attainment of a steady state. Our previous hydrodynamic studies in the $\mathrm{OMT}^{23}$ support the well-mixed assumption for each cavity of the OMT in the range of $f$ and $x_{0}$ herein considered (Table 2); thus, $x_{\mathrm{O}_{2}}{ }^{\text {out }}$ was taken as uniform around the micro-optrode's tip (i.e., as mixing cup "concentration").

The micro-optrode was appropriately calibrated by continuously flowing deaerated (oxygen saturation $=0 \%$ ) and oxygen saturated (oxygen saturation $=100 \%$ ) distilled water in the presence of smooth fluid oscillations (say $f$ and $x_{0}$ equal to 10 $\mathrm{s}^{-1}$ and $1 \mathrm{~mm}$, respectively) by bubbling air and nitrogen, respectively, in the water-supplying tank. The DO concentration in the tank was monitored using an oxygen electrode $(12 \mathrm{~mm}$ oxygen probe, Mettler-Toledo, Switzerland). Values of $K_{\mathrm{SV}}$ and $I_{0}$ from eq 2 were determined by Avasoft full software (Avantes, Eerbeek, The Netherlands).

The OMT was covered with aluminum foil at the measuring point to reduce the signal noise due to the environmental light. Poly(vinyl chloride) (PVC) tubes were used in all the setup and fitted with rigid PVC connectors, thus minimizing gas diffusion through the tube walls. Experiments were performed at the room temperature (i.e., $20^{\circ} \mathrm{C}$ ) and at least in duplicate for the different combinations of $f$ and $x_{0}$ shown in Table 2, covering $R e_{\mathrm{o}}$ numbers in the range of $0-1651$. The effect of the liquid net flow Reynolds number $\left(R e_{\mathrm{n}}=\right.$ $v_{\mathrm{L}} d \rho / \mu \approx 9.0$ ) on the mixing intensity within the OMT is considered negligible in comparison with the values of $R e_{0}$ achieved in the experiments.

2.4. Experimental Measurement of Gas Holdup. The volume fraction of the gas phase (the gas holdup, $\varepsilon_{\mathrm{G}}$ ) was measured for the same combinations of $f$ and $x_{0}$ shown in Table 2 by recording the changes in the liquid height from the tube OMT1 using a fine scaled $( \pm 0.5 \mathrm{~mm})$ plain pipe with $6 \mathrm{~mm}$ internal diameter fitted to the outlet of the tube, similarly to the procedure followed by Oliveira and $\mathrm{Ni}^{20}{ }^{20}$ The precision of this setup allowed an estimation of $\varepsilon_{\mathrm{G}}$ in most experiments with a final error $\leq 5 \%$. A $6 \mathrm{~mm}$ diameter was chosen for the plain pipe to avoid bubble retention after the outlet of the mesotube, thus maximizing the accuracy of $\varepsilon_{\mathrm{G}}$ measurement. The procedure involved measuring a liquid level $h_{0}$ in a fine scale marked on the plain pipe in the absence of gas and the corresponding level, $h$, when gas was continuously introduced at the same value of $Q_{\mathrm{G}}$. Two different modes of operation were tested: (a) continuous gas phase and continuous liquid phase and (b) continuous gas phase and batch liquid phase. In the later case, the liquid level was initially fixed at a stable level $\left(h_{0}\right)$. Then, the gas inlet valve was opened and the final liquid level $(h)$ was measured at the steady state. This final steady state was achieved after some minutes for the majority of the combinations of $f$ and $x_{0}$, but it took longer for either very low $\left(\leq 3 \mathrm{~s}^{-1}\right)$ or very high $\left(\geq 15 \mathrm{~s}^{-1}\right)$ values of $f$.

In the presence of the continuous flow of the liquid phase, a reverse proceeding was applied: the OMT was operated for 5-10 min at the desired values of $f, x_{0}, Q_{\mathrm{L}}$, and $Q_{\mathrm{G}}$. Then, the fluid level was fixed $(h)$ simultaneously with the water and air 


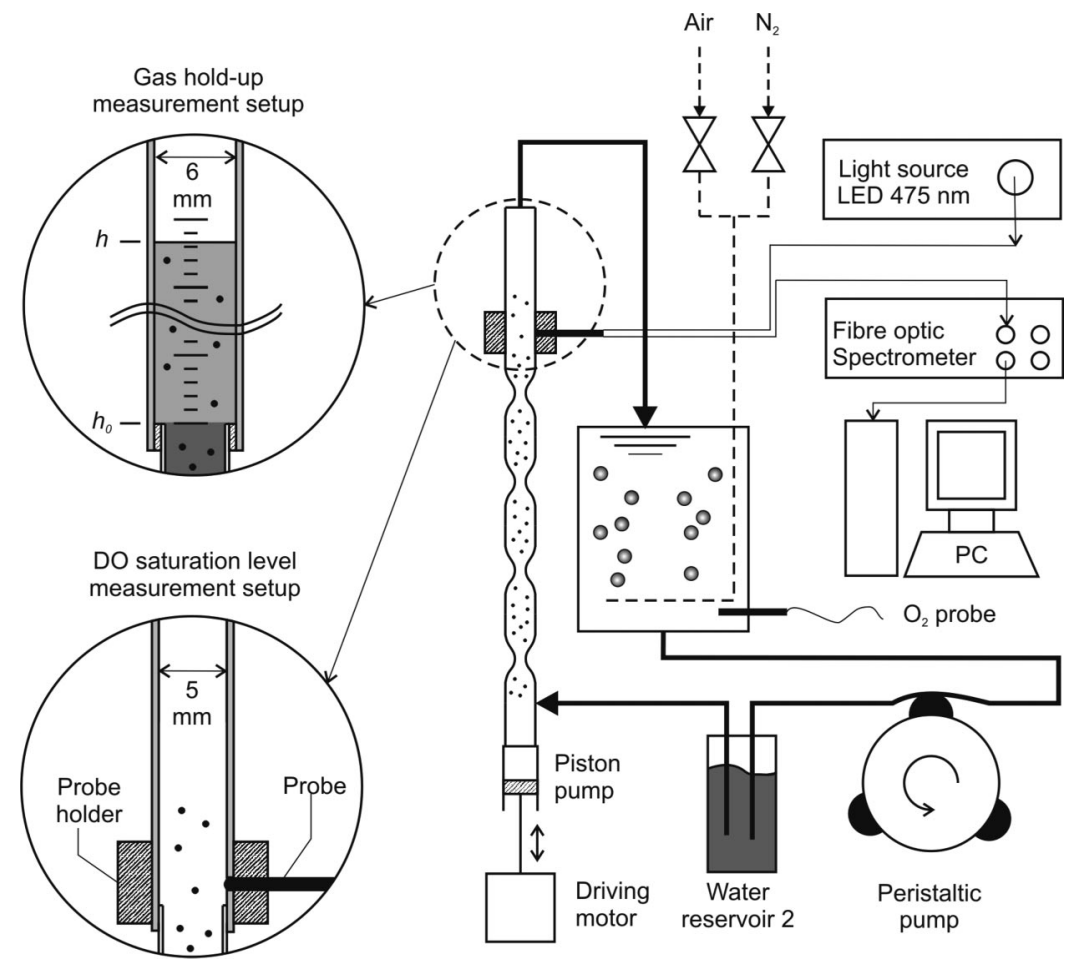

Figure 2. Experimental setup used in the gas-liquid oxygen mass transfer studies.

Table 2. Averaged Degree of Oxygen Utilization $\left(\eta_{\mathrm{O}_{2}}\right)$ in the Vertical OMT2, at Increasing Values of Fluid Oscillation Frequency $(f)$, Center-to-Peak Amplitude $\left(x_{0}\right)$, and Respective Oscillatory Reynolds Number $\left(R e_{0}\right)$; the Axial Dispersion Coefficient $\left(D_{\mathrm{L}}\right)$ and the Dimensionless Axial Dispersion Number $\left(\boldsymbol{P}_{\mathrm{a}}=v_{\mathrm{L}} \cdot L / D_{\mathrm{L}}\right)$ Were Estimated from the Previous Liquid-Phase Studies As Reported by Reis et al. ${ }^{23}$

\begin{tabular}{ccrccc}
\hline$f\left(\mathrm{~s}^{-1}\right)$ & $x_{0}(\mathrm{~mm})$ & $R e_{\mathrm{o}}$ & $D_{\mathrm{L}} \times 10^{6}\left(\mathrm{~m}^{2} \mathrm{~s}^{-1}\right)$ & $P_{\mathrm{a}}$ & $\eta_{\mathrm{O}_{2}}(\%)$ \\
\hline 0 & 0 & 0 & 138 & 1.18 & 3.6 \\
0.5 & 3 & 41 & 44 & 3.67 & 3.5 \\
0.5 & 7.5 & 103 & 89 & 1.85 & 3.7 \\
0.5 & 10 & 138 & 85 & 1.92 & 4.0 \\
0.5 & 15 & 206 & 33 & 4.83 & 4.1 \\
0.5 & 20 & 275 & 35 & 4.65 & 4.3 \\
1 & 3 & 83 & 12 & 1.36 & 4.6 \\
1 & 7.5 & 206 & 46 & 3.53 & 4.8 \\
1 & 10 & 275 & 43 & 3.73 & 6.5 \\
1 & 15 & 413 & 126 & 1.29 & 8.0 \\
1 & 20 & 550 & 204 & 0.81 & 10.3 \\
2 & 3 & 165 & 220 & 0.74 & 5.1 \\
2 & 7.5 & 413 & 149 & 1.07 & 7.4 \\
2 & 10 & 550 & 121 & 1.31 & 9.5 \\
2 & 15 & 825 & 283 & 0.58 & 10.4 \\
2 & 20 & 1101 & 462 & 0.36 & 11.0 \\
3 & 3 & 248 & 366 & 0.44 & 5.3 \\
3 & 7.5 & 619 & 314 & 0.51 & 8.6 \\
3 & 10 & 825 & 262 & 0.61 & 10.8 \\
3 & 15 & 1238 & 651 & 0.25 & 12.0 \\
3 & 20 & 1651 & 676 & 0.24 & 12.0
\end{tabular}

shutting down. The final liquid level $\left(h_{0}\right)$ was measured after rinsing all the bubbles out of the tube.

The gas holdup $\left(\varepsilon_{\mathrm{G}}\right)$ was calculated from the volume change $(\Delta V)$ by

$$
\varepsilon_{\mathrm{G}}=\frac{\Delta V}{V}
$$

where $\Delta V=\left(h-h_{0}\right) \pi / 4 \times(0.006 \mathrm{~m})^{2}$. The main advantage of this procedure was its easy implementation. The results of gas holdup for batch-mode determination are herein reported due to the major importance of knowing the operability range of the OMT when it is operated as a batch mixing device for sustaining, e.g., aerobic growth of cells.

\section{Modeling of Oxygen Mass Transport in the OMT}

Considering oxygen mass transfer between the air and liquid phases, two partial differential equations can be written to predict the oxygen concentrations over time and position in these two phases. Taking the values for steady state (i.e., when enough time has elapsed since the beginning of the experiment), a molar balance to DO in the liquid phase over an element $\mathrm{d} l$ can be written in terms of the convective and the diffusion flow as follows,

$$
\frac{\partial \bar{o}_{\mathrm{L}}}{\partial t}=0=-v_{\mathrm{L}} \frac{\partial \bar{o}_{\mathrm{L}}}{\partial l}+\left(1-\varepsilon_{\mathrm{G}}\right) D_{\mathrm{L}} \frac{\partial^{2} \bar{o}_{\mathrm{L}}}{\partial l^{2}}+k_{\mathrm{L}} a\left(\bar{o}_{\mathrm{L}}^{*}-\bar{o}_{\mathrm{L}}\right)
$$

where $D_{\mathrm{L}}$ is the eddy (or axial) dispersion coefficient and the term $\left(o_{\mathrm{L}}^{*}-\bar{o}_{\mathrm{L}}\right)$ is the "driving force" for oxygen mass transfer given as mixing cup concentrations.

The initial condition for the liquid phase at the inlet is

$$
\left.v_{\mathrm{L}} \bar{o}_{\mathrm{L}}\right|_{l=0}=\left(1-\varepsilon_{\mathrm{G}}\right) D_{\mathrm{L}} \frac{\partial \bar{o}_{\mathrm{L}}}{\partial l} l=0
$$

and the appropriate exit boundary condition is

$$
\left(1-\varepsilon_{\mathrm{G}}\right) D_{\mathrm{L}} \frac{\partial \bar{o}_{\mathrm{L}}}{\partial l}{ }_{l=L}=0
$$

Neglecting the gas backmixing, the differential equation for the oxygen balance in the gas phase $\left(\bar{o}_{\mathrm{G}}\right)$ can be written as

$$
\frac{\partial \bar{o}_{\mathrm{G}}}{\partial t}=0=\frac{\partial}{\partial l}\left(v_{\mathrm{SG}} \cdot \bar{o}_{\mathrm{G}}\right)+k_{\mathrm{L}} a\left(\bar{o}_{\mathrm{L}}^{*}-\bar{o}_{\mathrm{L}}\right)
$$

where $v_{\mathrm{SG}}$ is the mean superficial gas velocity $\left(\mathrm{m} \mathrm{s}^{-1}\right)$ and simultaneously with $\bar{o}_{\mathrm{L}}^{*}$ depends on the hydrostatic pressure in the tube. 
The boundary and initial condition for the gas phase is

$$
\bar{o}_{\mathrm{G}} \mathrm{l}_{l=0}=\alpha \bar{o}_{\mathrm{L}}^{*}(0)
$$

where $\bar{o}_{\mathrm{L}}^{*}(0)$ is the saturation oxygen concentration in equilibrium with the partial pressure of oxygen in the sparging air at the experimental pressure and temperature conditions, according to Henry's law, and $\alpha$ is a dimensionless factor converting the molar fraction of oxygen in the gas phase to molar concentration in the total volume of the tube.

Solving together eqs 4 and 7 , the overall $k_{\mathrm{L}} a$ can actually be determined by taking a single measurement point of DO concentration (i.e., using the values $x_{\mathrm{O}_{2}}{ }^{\text {out }}$ measured with the micro-optrode), assuming both $D_{\mathrm{L}}$ and $\varepsilon_{\mathrm{G}}$ are known as well as the DO concentration in the feeding tank. The values of $\varepsilon_{\mathrm{G}}$ were experimentally determined in this study, while the values for $D_{\mathrm{L}}$ were made available from previous studies in the $\mathrm{OMT}^{23}$ at the same range of oscillating conditions. The mean values of $D_{\mathrm{L}}$ for each combination of $f$ and $x_{0}$ are summarized in Table 2 . Note $D_{\mathrm{L}}$ values do not correlate with the mixing intensity as both the radial mixing and the fluid backflow (imposed by the reciprocating flow) do contribute to the global axial dispersion coefficient; in general, low $x_{0}$ and high $f$ leads to plug-flow behavior (i.e., minimum values of $D_{\mathrm{L}}$ ).

There are some assumptions in writing eqs 4-8. Closed boundaries were considered for the OMT as previously demonstrated by the residence time distribution studies. ${ }^{23}$ Flow and dispersion in the radial and angular directions are assumed to be negligible, and the gas phase flows in a plugflow pattern. The last is a very common assumption on $k_{\mathrm{L}} a$ studies in, e.g., bubble columns, ${ }^{24}$ but this is in fact a careful assumption as it leads to underestimated values of $k_{\mathrm{L}} a$. The dispersion coefficients for liquid-phase flow, $D_{\mathrm{L}}$, are not significantly affected by the presence of the gas phase; the values of $\varepsilon_{\mathrm{G}}$ for the continuous operation were lower than $5 \%$ at any of the experimental conditions herein tested, as will be shown below. Operating conditions such as gas flow rate and liquid volume are constant; therefore, gas holdup, gas velocity, and liquid velocity remain constant throughout the tube. The differential hydrostatic pressure has been ignored, which is reasonable considering the small height of the OMT; this also supports the assumption of a uniform $\varepsilon_{\mathrm{G}}$ for "steady-state" operation.

Taking the dimensionless form with $z=l / L, P_{\mathrm{a}}=v_{\mathrm{L}} L / D_{\mathrm{L}}$, and substituting $\bar{y}_{\mathrm{L}}=\bar{o}_{\mathrm{L}}-\bar{o}_{\mathrm{L}}^{*}$, eq 4 becomes

$$
\left(1-\varepsilon_{\mathrm{G}}\right) \frac{1}{P_{\mathrm{a}}}\left[\frac{\partial^{2} \bar{y}_{\mathrm{L}}}{\partial z^{2}}+\frac{\partial^{2} \bar{o}_{\mathrm{L}}^{*}}{\partial z^{2}}\right]-\left[\frac{\partial \bar{y}_{\mathrm{L}}}{\partial z}+\frac{\partial \bar{o}_{\mathrm{L}}^{*}}{\partial z}\right]-\tau_{\mathrm{L}} k_{\mathrm{L}} a \bar{y}_{\mathrm{L}}=0
$$

while eq 7 may be written as

$$
\frac{\partial \bar{o}_{\mathrm{G}}}{\partial z}=\tau_{\mathrm{G}} k_{\mathrm{L}} a \bar{y}_{\mathrm{L}}
$$

where $\tau_{\mathrm{L}}$ and $\tau_{\mathrm{G}}$ are the mean residence time of the liquid and gas phases in the OMT, respectively, and can be determined from the following relations: $\tau_{\mathrm{L}}=L / v_{\mathrm{L}}$ and $\tau_{\mathrm{G}}=L / v_{\mathrm{SG}}$.

The gas concentration in the total volume can also be represented by

$$
\bar{o}_{\mathrm{G}}=y_{\mathrm{O}_{2}} \cdot \frac{\varepsilon_{\mathrm{G}}}{1-\varepsilon_{\mathrm{G}}} \cdot \frac{P}{R T}
$$

If enough time is elapsed, the molar fraction of oxygen in the gas phase at "steady state" in eq $10 b\left(y_{\mathrm{O}_{2}}\right)$ will achieve equilibrium with the saturation concentration of DO in the liquid phase $\left(\bar{o}_{\mathrm{L}}^{*}\right)$, according to Henry's law,

$$
y_{\mathrm{O}_{2}}=\frac{k_{\mathrm{c}}^{\prime}}{P} \bar{o}_{\mathrm{L}}^{*}
$$

where $k_{\mathrm{c}}^{\prime}$ is the Henry's constant based on molar concentrations and is equal to $736.85 \mathrm{~atm} \mathrm{~L} \mathrm{~mol}{ }^{-1}$ at the experimental temperature and pressure conditions $\left(20^{\circ} \mathrm{C}\right.$ and $\left.1 \mathrm{~atm}\right)$.

Thus, eq 10a can be rearranged to

$$
\frac{\partial \bar{o}_{\mathrm{L}}^{*}}{\partial z}=\frac{1}{\alpha} \tau_{\mathrm{G}} k_{\mathrm{L}} a \bar{y}_{\mathrm{L}}
$$

where

$$
\alpha=\frac{\bar{o}_{\mathrm{G}}}{\bar{o}_{\mathrm{L}}^{*}}=\frac{k_{\mathrm{c}}^{\prime}}{P} \cdot \frac{\varepsilon_{\mathrm{G}}}{1-\varepsilon_{\mathrm{G}}} \cdot \frac{P}{R T}
$$

From eq $11 \mathrm{a}$, the derivatives $\partial \bar{o}_{\mathrm{L}}^{*} / \partial z$ and $\partial^{2-} o_{\mathrm{L}}^{*} / \partial z^{2}$ can be determined and substituted in eq 9, thus obtaining the following equation:

$$
\begin{aligned}
&\left(1-\varepsilon_{\mathrm{G}}\right) \frac{1}{P_{\mathrm{a}}} \frac{\partial^{2} \bar{y}_{\mathrm{L}}}{\partial z^{2}}-\left[1-\left(1-\varepsilon_{\mathrm{G}}\right) \frac{1}{P_{\mathrm{a}} \alpha} \tau_{\mathrm{G}} k_{\mathrm{L}} a\right] \frac{\partial \bar{y}_{\mathrm{L}}}{\partial z}-\left[\left(\frac{1}{\alpha} \tau_{\mathrm{G}}+\right.\right. \\
&\left.\left.\tau_{\mathrm{L}}\right) k_{\mathrm{L}} a\right] \bar{y}_{\mathrm{L}}=0(12)
\end{aligned}
$$

This is a second order, linear, homogeneous, ordinary differential equation (ODE) with constant coefficients, and for the boundary conditions given in eqs 5 and 6 , it can be demonstrated that the solution is

$$
\begin{array}{r}
\bar{y}_{\mathrm{L}}(z)=o_{\mathrm{L}}^{*}(0)\left[\frac { \gamma _ { 2 } } { w _ { 2 } \gamma _ { 1 } \operatorname { e x p } ( \lambda _ { 1 } ) - w _ { 2 } \gamma _ { 2 } \operatorname { e x p } ( \lambda _ { 2 } ) } \left(\exp \left(\lambda_{2}+\lambda_{1} z\right)-\right.\right. \\
\left.\left.\frac{w_{1}}{w_{2}} \exp \left(\lambda_{2}+\lambda_{2} z\right)\right)-\frac{1}{w_{2}} \exp \left(\lambda_{2} z\right)\right](13 \mathrm{a})
\end{array}
$$

with $\bar{o}_{\mathrm{L}}^{*}(0)=y_{\mathrm{O}_{2}}(0) \cdot P / k_{\mathrm{c}}^{\prime}$ and $y_{\mathrm{O}_{2}}(0)$ being the molar fraction of oxygen in the sparging air and equal to $0.20948 \mathrm{~mol}_{\mathrm{O}_{2}} / \mathrm{mol}_{\text {air }}$ for atmospheric air. by

In eq 13 , the parameters $\lambda_{1}, \lambda_{2}, \gamma_{1}, \gamma_{2}, w_{1}$, and $w_{2}$ are given

$$
\begin{aligned}
\lambda_{1}= & \frac{P_{\mathrm{a}}}{2\left(1-\varepsilon_{\mathrm{G}}\right)}\left[1-\left(1-\varepsilon_{\mathrm{G}}\right) \frac{1}{P_{\mathrm{a}} \alpha} \tau_{\mathrm{G}} k_{\mathrm{L}} a+\right. \\
& \sqrt{\left.\left(1-\left(1-\varepsilon_{\mathrm{G}}\right) \frac{1}{P_{\mathrm{a}} \alpha} \tau_{\mathrm{G}} k_{\mathrm{L}} a\right)^{2}+4\left(1-\varepsilon_{\mathrm{G}}\right) \frac{1}{P_{\mathrm{a}} \alpha}\left(\frac{1}{\alpha} \tau_{\mathrm{G}}+\tau_{\mathrm{L}}\right) k_{\mathrm{L}} a\right]}
\end{aligned}
$$

$$
\begin{aligned}
\lambda_{2}= & \frac{P_{\mathrm{a}}}{2\left(1-\varepsilon_{\mathrm{G}}\right)}\left[1-\left(1-\varepsilon_{\mathrm{G}}\right) \frac{1}{P_{\mathrm{a}} \alpha} \tau_{\mathrm{G}} k_{\mathrm{L}} a-\right. \\
& \left.\sqrt{\left(1-\left(1-\varepsilon_{\mathrm{G}}\right) \frac{1}{P_{\mathrm{a}} \alpha} \tau_{\mathrm{G}} k_{\mathrm{L}} a\right)^{2}+4\left(1-\varepsilon_{\mathrm{G}}\right) \frac{1}{P_{\mathrm{a}} \alpha}\left(\frac{1}{\alpha} \tau_{\mathrm{G}}+\tau_{\mathrm{L}}\right) k_{\mathrm{L}} a}\right]
\end{aligned}
$$

$$
\gamma_{1}=\lambda_{1}+\frac{1}{\alpha} \tau_{\mathrm{G}} k_{\mathrm{L}} a
$$

$$
\gamma_{2}=\lambda_{2}+\frac{1}{\alpha} \tau_{\mathrm{G}} k_{\mathrm{L}} a
$$

$w_{1}=1-\left(1-\varepsilon_{\mathrm{G}}\right) \frac{1}{P_{\mathrm{a}}} \gamma_{1}$

$$
w_{2}=1-\left(1-\varepsilon_{\mathrm{G}}\right) \frac{1}{P_{\mathrm{a}}} \gamma_{2}
$$


Equation 11a can be integrated in order to distance $z$ after substituting the term $\bar{y}_{\mathrm{L}}$ given by eq 13 , thus yielding

$$
\begin{gathered}
\bar{o}_{\mathrm{L}}^{*}(z)=o_{\mathrm{L}}^{*}(0)\left[1+\frac{\tau_{\mathrm{G}} k_{\mathrm{L}} a}{\alpha \lambda_{1}} \frac{\gamma_{2}\left(\exp \left(\lambda_{2}+\lambda_{1} z\right)-\exp \left(\lambda_{2}\right)\right)}{w_{2} \gamma_{1} \exp \left(\lambda_{1}\right)-w_{2} \gamma_{2} \exp \left(\lambda_{2}\right)}-\right. \\
\left.\frac{\tau_{\mathrm{G}} k_{\mathrm{L}} a w_{1}}{\alpha w_{2} \lambda_{2}} \frac{\gamma_{2}\left(\exp \left(\lambda_{2}+\lambda_{2} z\right)-\exp \left(\lambda_{2}\right)\right)}{w_{2} \gamma_{1} \exp \left(\lambda_{1}\right)-w_{2} \gamma_{2} \exp \left(\lambda_{2}\right)}-\frac{\tau_{\mathrm{G}} k_{\mathrm{L}} a\left(\exp \left(\lambda_{2}\right)-1\right)}{\alpha w_{2} \lambda_{2}}\right]
\end{gathered}
$$

The DO concentration in the liquid phase $\left(\bar{o}_{\mathrm{L}}\right)$ can now be simply obtained with eqs $13 \mathrm{a}-\mathrm{g}$ and 14 using the initial substitution previously done in eq 9:

$$
\bar{o}_{\mathrm{L}}(z)=\bar{y}_{\mathrm{L}}(z)+o_{\mathrm{L}}^{*}(z)
$$

It can be proved that the two functions $\bar{y}_{\mathrm{L}}(z)$ and $\bar{o}_{\mathrm{L}}^{*}(z)$ defined by eqs $13 \mathrm{a}$ and 14 above increase/decrease monotonically with $z$, and that $\bar{o}_{\mathrm{L}}(z)$ given by eq 15 is always positive.

By setting $z=1$ in eqs $13 \mathrm{a}-15$, the modeled value $\bar{o}_{\mathrm{L}} \mathrm{l}_{z=1}$ can be compared with the DO concentration given by $x_{\mathrm{O}_{2}}{ }^{\text {out }}$ by iteratively defining a proper value for $k_{\mathrm{L}} a$. This was done using Excel's Solver tool and assuming a residual of $0.001 \%$ for convergence of the solution.

Alternatively, from a global mass balance to the liquid phase between the inlet and the outlet of the OMT, the oxygen molar fraction (or the partial pressure) for the exit gas, $y_{\mathrm{O}_{2}} \mathrm{l}_{z=1}$, can be determined from the following:

$$
y_{\mathrm{O}_{2} z=1}=\frac{y_{\mathrm{O}_{2}}(0) Q_{\mathrm{G}} \frac{P}{R T}-x_{\mathrm{O}_{2}}^{\text {out }} \bar{o}_{\mathrm{L}}^{*}(0) Q_{\mathrm{L}}}{Q_{\mathrm{G}} \frac{P}{R T}-x_{\mathrm{O}_{2}}^{\text {out }} \bar{o}_{\mathrm{L}}^{*}(0) Q_{\mathrm{L}}}
$$

Actually, $\bar{o}_{\mathrm{L}}^{*} \mathrm{I}_{z=1}=y_{\mathrm{O}_{2}} \mathrm{I}_{z=1} \cdot P / k_{\mathrm{c}}^{\prime}$ can also be used as the target in Solver's tool, but the selection of $\bar{o}_{\mathrm{L}} \mathrm{I}_{z=1}$ as the convergence criterion is wiser as it presents lower propagated errors. In the last case, the converged values for $\bar{o}_{\mathrm{L}} \mathrm{L}_{z=1}$ yielded an estimation of $\left.\bar{o}_{\mathrm{L}} *\right|_{z=1}$ within an error of $\pm 2 \%$ in relation to the experimental value determined from eq 16.

\section{Results and Discussion}

4.1. Effect of Fluid Oscillations on Gas Holdup for Continuous and Batch Operation. Figure 3 summarizes the averaged values of $\varepsilon_{\mathrm{G}}$ in the vertical OMT1 for continuous and batch flow of the liquid phase. In both cases, a continuous gas flow rate of $0.28 \mathrm{~mL} \mathrm{m^{-1 }}$ was used. Note the 1 order of magnitude difference in $y$-axis for parts a and $\mathrm{b}$ of Figure 3 .

In the presence of a continuous liquid flow rate (Figure $3 a$ ), the $\varepsilon_{\mathrm{G}}$ values were $<5 \%$, which is less than one-third of the value given by the ratio $Q_{\mathrm{G}} /\left(Q_{\mathrm{G}}+Q_{\mathrm{L}}\right)$ (i.e., $\left.\sim 15 \%\right)$. This is because of the gas buoyancy, giving a lower residence time to the gas phase in comparison with the residence time of the liquid phase within the reactor's volume. Note that the contacting (residence) time of bubbles $\left(\tau_{\mathrm{b}}\right)$ is given by the following, ${ }^{25}$

$$
\tau_{\mathrm{b}}=\frac{L \varepsilon_{\mathrm{G}}}{v_{\mathrm{SG}}}
$$

and $v_{\mathrm{SG}}$ is based in this case on $d_{\text {mean }}=4.0 \mathrm{~mm}$. The net flow of fluid facilitates the upward movement (rising) of bubbles, promoting the gas disengagement at the top of the OMT.

In the absence of the continuous liquid flow rate (Figure $3 \mathrm{~b}$ ), the values obtained for $\varepsilon_{\mathrm{G}}$ were very high (up to $90 \%$ of gas voidage), especially when operated at the lowest value of $x_{0}$ (i.e., $0.5 \mathrm{~mm}$ ). This flow regime (slug flow) is generally undesirable because it might result in increased evaporation of the liquid phase as well as in the damping of fluid oscillations within the reactor because of the gas compressibility. This relates to the presence of narrow constrictions in the OMT; however, it is possible to avoid it by operation at the highest possible values of $x_{0}$, preferably $3 \mathrm{~mm}$, resulting for this last case in $\varepsilon_{\mathrm{G}}$ values in the range of $1-30 \%$.

For both situations presented in Figure 3, the effects of $f$ and $x_{0}$ on $\varepsilon_{\mathrm{G}}$ are quite similar and demonstrate the major effect of oscillatory flow mixing on controlling the gas flow patterns in the OMT. For the $x_{0}$ values considered in this study, the values of $\varepsilon_{\mathrm{G}}$ were at a minimum for $f=7.5$ and $10 \mathrm{~s}^{-1}$. Globally, the lowest value of $\varepsilon_{\mathrm{G}}$ was $0.013 \pm 0.003$ (i.e., a volume gas fraction of $\sim 1.3 \%$ ), obtained at $f=10 \mathrm{~s}^{-1}$ and $x_{0}=3 \mathrm{~mm}$.

In general, two patterns were observed for the effect of $f$ on $\varepsilon_{\mathrm{G}}$ for $x_{0} \geq 1 \mathrm{~mm}$ : at low values of $f$, the value of $\varepsilon_{\mathrm{G}}$ decreases with increasing $f$; on the other hand, for $f>10 \mathrm{~s}^{-1}$, the values of $\varepsilon_{\mathrm{G}}$ increased with the increase of $f$. Although two patterns were also observed by Oliveira and $\mathrm{Ni}^{20}$ for a sparged OFR, the gas-phase dynamics in this scaled-down geometry seems clearly distinct from that observed in a $50 \mathrm{~mm}$ internal diameter OFR.

In the absence of fluid oscillations (i.e., $f=0$ and $x_{0}=0$ ), bubbles with a large diameter (in the same order of magnitude of $d$ ) were forming at the sparger in the OMT (results not

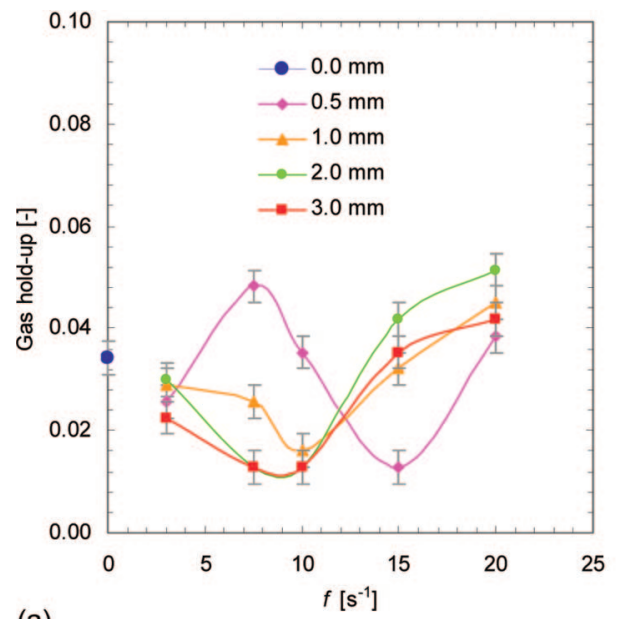

(a)

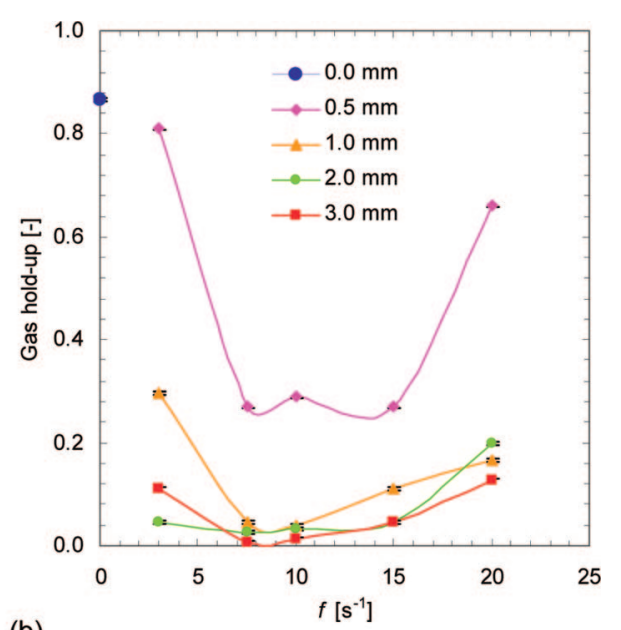

(b)

Figure 3. Effect of fluid oscillation frequency $(f)$ and center-to-peak amplitude $\left(x_{0}\right)$ on gas holdup $\left(\varepsilon_{\mathrm{G}}\right)$ measured with the OMT2 for a $Q_{\mathrm{G}}=0.28 \mathrm{~mL}$ min ${ }^{-1}$ in the (a) presence and (b) absence of $Q_{\mathrm{L}}=1.58 \mathrm{~mL} \mathrm{~min}^{-1}$. The error bars indicate the range of one standard deviation. 
shown). When crossing the narrow constrictions, those bubbles experienced a drag force impeding their progress toward the exit, therefore increasing their mean residence time and leading to higher values of $\varepsilon_{\mathrm{G}}$. When fluid oscillations are superimposed onto the continuous liquid flow, the movement of rising bubbles is facilitated at low values of $f$ and their mean residence time in the OMT is reduced. The upward and downward movement of the fluid causes bubbles breakage. Some of the bubbles will have their diameter substantially reduced to a value smaller than the orifice free diameter (i.e., $<1.6 \mathrm{~mm}$ ), thus achieving a nearly blockage-free, upward motion that results in lower values of $\varepsilon_{\mathrm{G}}$ and $\tau_{\mathrm{b}}$

For $f>10 \mathrm{~s}^{-1}$, the high energy dissipation from the fluid oscillations will presumably lead to the coexistence of bubble breakage and coalescence phenomena, on top of a particular feature: the bubble "retention" as reported for OFRs ${ }^{20}$ or the bubble "levitation" as reported by Ellenberger and Krishna ${ }^{14}$ for a plain bubble column. The tiny bubbles resulting from the enhanced breakage rate have a low rising velocity, eventually in the order of $0.1 \mathrm{~m} \mathrm{~s}^{-1}$. The downward movement of the fluid produces an average peak velocity in the order of $0.01-0.4 \mathrm{~m}$ $\mathrm{s}^{-1}$, coupled with a strong recirculation of the fluid through intensive vortex rings. This clearly results in the enhancement of $\varepsilon_{\mathrm{G}}$ and the reduction of the rise velocity of the bubbles, and bubbles can actually follow the liquid flow. This is illustrated in Figure 4, where the typical pathlines followed by the bubbles can be identified at the interconstriction region for one complete oscillation cycle (a CCD camera was exposed to 1 full period of oscillation, i.e., $1 / f)$.

In summary, the $\varepsilon_{\mathrm{G}}$ values herein presented for the OMT are slightly higher than those reported by Oliveira and $\mathrm{Ni}^{20}$ for the OFR, using similar mixing intensities (i.e., similar values of $R e_{\mathrm{O}}$ ): a minimum value of $\varepsilon_{\mathrm{G}}$ equal to 0.01 was reported for $v_{\mathrm{SG}}=1.06 \mathrm{~mm} \mathrm{~s}^{-1}$. The internal geometry (in particular the small $d$ and the narrow constrictions) is a major factor distinguishing the gas-phase dynamics in the scaled-down OMT in comparison with that in a sparged OFR.

4.2. Effect of Fluid Oscillations on the Oxygen MassTransfer Coefficient. The several experiments carried out with the vertical OMT1 in the presence of continuous gas and liquid flow rates have shown a $100 \%$ saturation in DO concentration at the reactor's outlet for $f>7.5 \mathrm{~s}^{-1}$ and $x_{0}>0.5 \mathrm{~mm}$. This is clearly seen in the plateau represented in Figure 5a. The model developed for oxygen mass transport cannot be used in this case to estimate the effective $k_{\mathrm{L}} a$ in the OMT; more measurements of $x_{\mathrm{O}_{2}}$ would be required through the axial distance of the tube. Thus, further experiments where conducted with the shorter (75 mm length) OMT2. This tube length was considered appropriate because it avoided the full saturation of DO in all of the operational conditions herein tested. Figure $5 \mathrm{~b}$ shows a similar behavior in DO saturation level at the outlet of OMT2 for increasing values of $f$ and $x_{0}$. Note that all DO values shown in Figure 4 represent the average of three measurements, and a maximum standard deviation of $3.5 \%$ was obtained between experimental duplicates. Oxygen mass transfer is strongly affected by the values of $f$ and $x_{0}$. The maximum value of DO concentration was registered at the highest values of $f$ and $x_{0}$ herein tested (i.e., $20 \mathrm{~s}^{-1}$ and $3 \mathrm{~mm}$, respectively), presumably due to the higher mixing intensity achieved at these fluid oscillation conditions. The plateau observed in Figure 5 for the highest values of $f$ and $x_{0}$ clearly suggests a decrease in the dissolved oxygen concentration throughout the OMT, consequently reducing the oxygen mass transfer by presenting a low "driving force" term $\left(\bar{o}_{\mathrm{L}}^{*}-\bar{o}_{\mathrm{L}}\right)$.

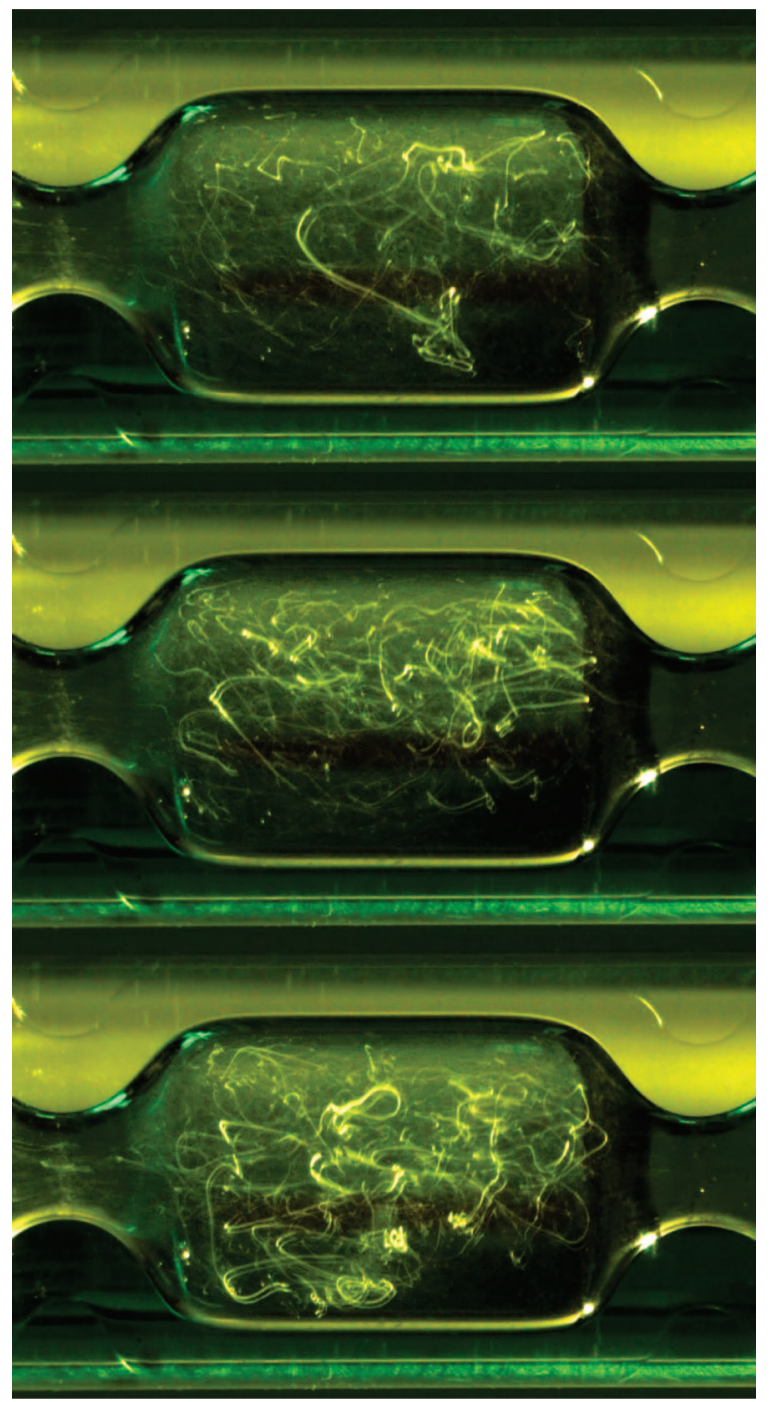

Figure 4. Pathlines defined by bubbles moving in a horizontal OMT for one complete oscillation cycle $\left(f=15 \mathrm{~s}^{-1}, x_{0}=2 \mathrm{~mm}\right)$.

Figure 6 summarizes the averaged values of $k_{\mathrm{L}} a$ estimated from the oxygen mass transfer model, considering the DO concentration values measured at the outlet of the OMT2 and assuming $\bar{o}_{\mathrm{L}} \mathrm{l}_{z=1}=x_{\mathrm{O}_{2}}{ }^{\text {out }}$ in eqs 14-16. The graphical rendering of the surface fitting the scattered data is based on Renka's triangulation routine. ${ }^{26}$ The $k_{\mathrm{L}} a$ values were clearly improved with increasing $f$ and $x_{0}$ at all the conditions herein tested. The effect of $x_{0}$ on $k_{\mathrm{L}} a$ is actually more significant than that of $f$ : doubling the values of $x_{0}$ induces a greater increase in $k_{\mathrm{L}} a$ then doubling the values of $f$. This happens because $x_{0}$ apparently controls the length of eddy generation along the reactor, following previous studies on mass transfer in a conventional $\mathrm{OFR}^{16}$ and agreeing with previous determinations of mixing times and residence time distributions in the OMT. ${ }^{23}$ Actually, such variance is already suggested by the different exponent terms in the two time-averaged power density $(P / V)$ prediction models most often considered in OFRs: the quasi-steady-state flow model, ${ }^{27}$ with $P / V \alpha$ $f^{3} x_{0}{ }^{3}$, which is valid for high $x_{0}$ and low $f(5-30 \mathrm{~mm}, 0.5-2$ $\left.\mathrm{s}^{-1}\right)$, and the eddy acoustic model, ${ }^{25} P / V \alpha f^{2} x_{0}{ }^{3}$, valid for high $f$ and low $x_{0}\left(1-5 \mathrm{~mm}, 3-14 \mathrm{~s}^{-1}\right)$.

The $k_{\mathrm{L}} a$ data in Figure 6 is to some extent analogous to the data reported by $\mathrm{Ni}$ et al. ${ }^{16}$ for a conventional OFR. Those authors have studied the $k_{\mathrm{L}} a$ for a sparged OFR using $f=3-12$ $\mathrm{s}^{-1}$ and $x_{0}=4-14 \mathrm{~mm}$ and have observed a similar trend in 

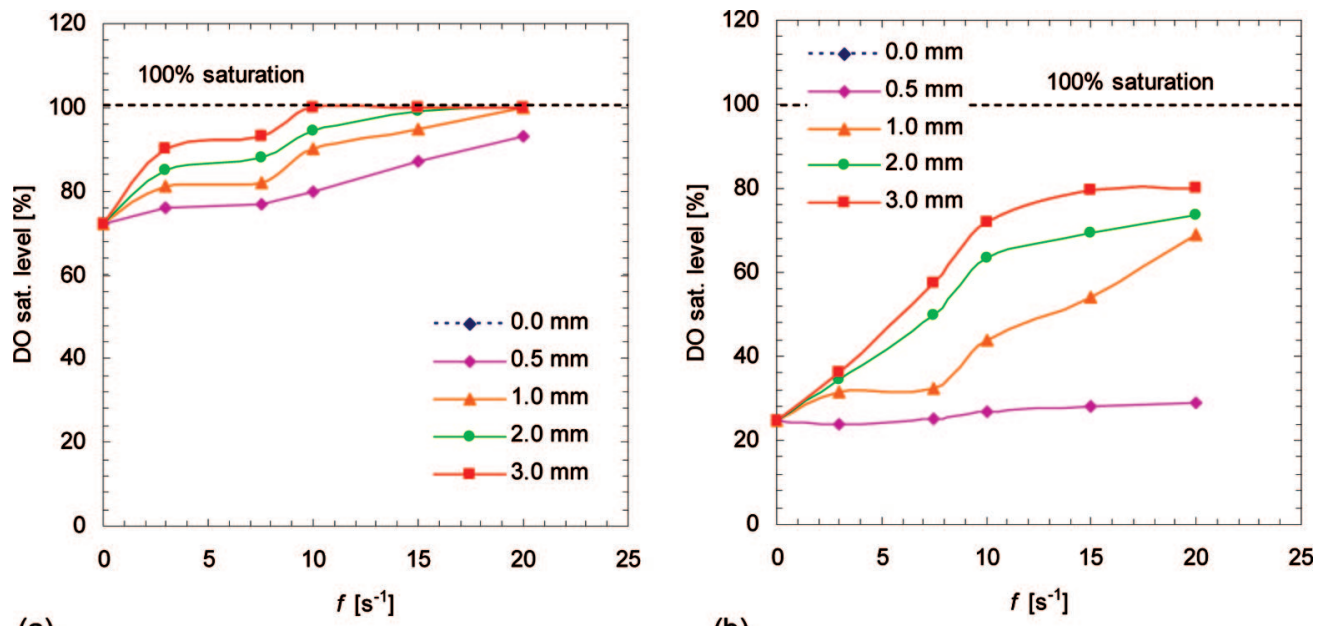

(a)

(b)

Figure 5. Effect of the fluid oscillation frequency $(f)$ and center-to-peak amplitude $\left(x_{0}\right)$ on the saturation levels of dissolved oxygen (DO) concentration for (a) OMT1 and (b) OMT2; $Q_{\mathrm{L}}=1.58 \mathrm{~mL} \mathrm{~min}^{-1}$ and $Q_{\mathrm{G}}=0.28 \mathrm{~mL} \mathrm{~min}^{-1}$.

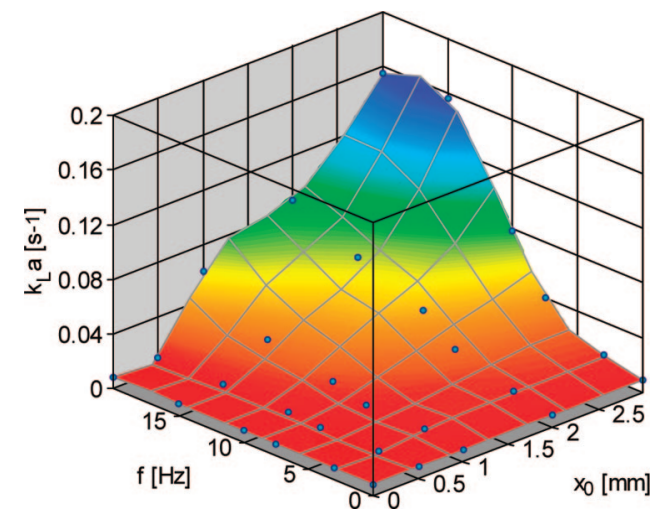

Figure 6. Effect of the fluid oscillation frequency $(f)$ and center-to-peak amplitude $\left(x_{0}\right)$ on the volumetric oxygen mass transfer coefficient $\left(k_{\mathrm{L}} a\right)$ in a vertical oscillatory mesotube; $Q_{\mathrm{L}}=1.58 \mathrm{~mL} \mathrm{~min}^{-1}$ and $Q_{\mathrm{G}}=0.28 \mathrm{~mL}$ $\min ^{-1}$.

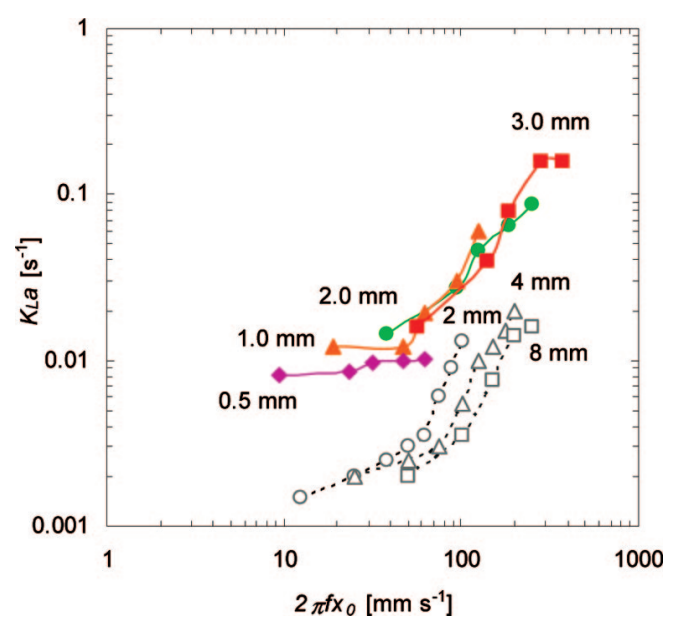

Figure 7. Comparison of the mean $k_{\mathrm{L}} a$ values in the OMT with $k_{\mathrm{L}} a$ values reported by Oliveira and $\mathrm{Ni}^{21}$ for a conventional $50 \mathrm{~mm}$ internal diameter OFR, at similar values of peak oscillating velocities (i.e., $2 \pi f x_{0}$ ).

$k_{\mathrm{L}} a$ with the increase of $f$, meaning that, in this range of fluid oscillation conditions, the flow patterns are quite similar in both the OFR and the OMT. ${ }^{1}$ The maximum $k_{\mathrm{L}} a=0.16 \pm 0.03 \mathrm{~s}^{-1}$ obtained with the OMT (using a $v_{\mathrm{SG}}=0.28 \mathrm{~mm} \mathrm{~s}^{-1}$ and a $R e_{\mathrm{O}}$ $=1651$ ) is very high when compared with the $k_{\mathrm{L}} a$ values reported for the OFR. In the latter case, a $k_{\mathrm{L}} a=0.01 \mathrm{~s}^{-1}$ was reported by Hewgill et al. ${ }^{12}$ for a similar value of $R e_{0}$, and a

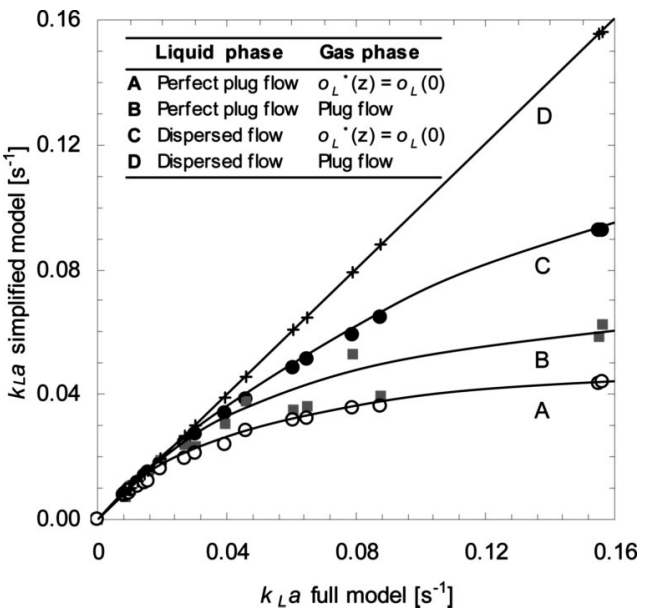

Figure 8. Effect of different simplifications (A-D) of liquid- and gasphase dynamics on the $k_{\mathrm{L}} a$ values estimated from the oxygen transport equations. Model D (or "full model") is the model described in the Experimental Apparatus and Procedures section and used to calculate $k_{\mathrm{L}} a$ values in Figure 6.

maximum $k_{\mathrm{L}} a=0.02 \mathrm{~s}^{-1}$ was obtained for $R e_{\mathrm{o}}=5000$. The $k_{\mathrm{L}} a$ enhancement obtained by the OMT is remarkable, especially when considering that the work of Hewgill et al. ${ }^{12}$ was performed using a 4-fold higher value of $v_{\mathrm{SG}}$ (i.e., $1.1 \mathrm{~mm} \mathrm{~s}^{-1}$ ). Also, Oliveira and $\mathrm{Ni}^{20}$ reported maximum values of $k_{\mathrm{L}} a=$ $0.017 \mathrm{~s}^{-1}$ for $v_{\mathrm{SG}}=1.06 \mathrm{~mm} \mathrm{~s}^{-1}$, and $k_{\mathrm{L}} a=0.04 \mathrm{~s}^{-1}$ for $v_{\mathrm{SG}}$ $=4.24 \mathrm{~mm} \mathrm{~s}^{-1}$, using $x_{0}=4 \mathrm{~mm}$ and $f=8 \mathrm{~s}^{-1}$, which are clearly lower than the values herein presented. Figure 7 compares the $k_{\mathrm{L}} a$ values obtained with the OMT with those reported by Oliveira and $\mathrm{Ni}^{21}$ for a similar range of peak oscillatory velocities (given by $2 \pi f x_{0}$ ). An average 5 -fold increase in $k_{\mathrm{L}} a$ was obtained with the OMT for the same value of peak oscillatory velocity, showing the higher efficiency of the small reactor for $\mathrm{O}_{2}$ mass-transfer purposes, especially when considering the difference in $v_{\mathrm{S}}$. Such improvement goes up some $\sim 11.4$-fold when the two reactors are compared for the same intensity of oscillatory flow mixing (i.e., $R e_{\mathrm{o}}$ ), as there is 1 order of magnitude separating the values of the two internal diameters.

The efficiency of oxygen mass transfer from the gas to the liquid phase in the OMT given by the ratio $\eta_{\mathrm{O}_{2}}=\left(\left.\bar{o}_{\mathrm{G}}\right|_{z=0}\right.$ $\left.-\bar{o}_{\mathrm{G}} \mathrm{I}_{z=1}\right) / \bar{o}_{\mathrm{G}} \mathrm{I}_{z=0}$ is remarkable as summarized in Table 2 . The oxygen uptake rates by the liquid phase were in the range 

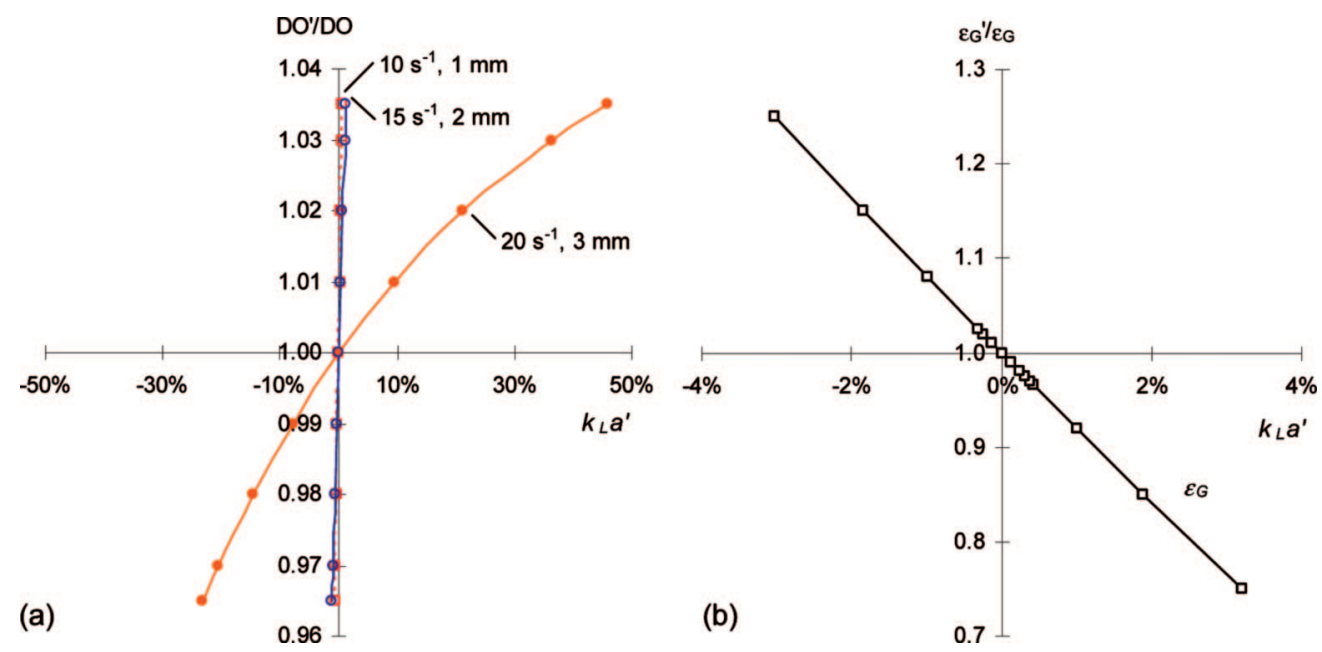

Figure 9. Sensibility analysis of $k_{\mathrm{L}} a$ values for variations in the dissolved oxygen concentration (DO) and gas holdup ( $\varepsilon_{\mathrm{G}}$ ) in the range given by the maximum standard deviation obtained between experimental duplicates.

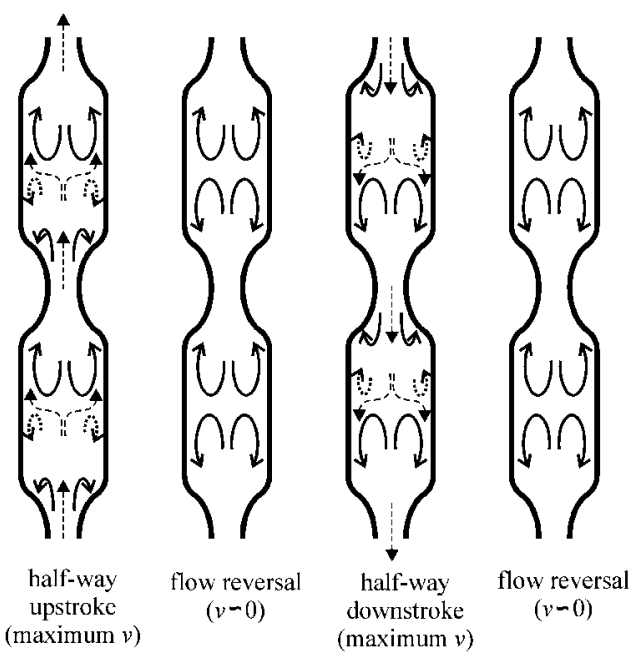

Figure 10. Typical flow patterns in the OMT. ${ }^{1}$

Table 3. Comparison of $k_{\mathrm{L}} a$ Values Obtained in the Vertical, Continuous OMT1 and in Conventional Gas-Liquid Contacting Vessels; $R e_{0}$ is the Oscillatory Reynolds Number and $v_{\mathrm{SG}}$ is the Mean Superficial Gas Velocity ${ }^{a}$

\begin{tabular}{llrll}
\hline $\begin{array}{c}\text { G-L } \\
\text { contacting } \\
\text { device }\end{array}$ & $k_{\mathrm{L}} a\left(\mathrm{~s}^{-1}\right)$ & \multicolumn{1}{c}{$R e_{\mathrm{o}}$} & $v_{\mathrm{SG}}\left(\mathrm{mm} \mathrm{s}^{-1}\right)$ & \multicolumn{1}{c}{ ref } \\
\hline OMT & 0.009 & 0 & 0.37 & this work \\
& 0.156 & 1651 & 0.37 & this work \\
OFR & 0.003 & 0 & 1.1 & Hewgill et al. ${ }^{12}$ \\
& 0.004 & 959 & 1.1 & Hewgill et al. \\
& 0.006 & 2510 & 1.1 & Hewgill et al. \\
& 0.017 & 5200 & 1.1 & Hewgill et al. ${ }^{12}$ \\
& 0.017 & 9743 & 1.06 & Oliveira and $\mathrm{Ni}^{21}$ \\
& 0.04 & 9743 & 4.24 & Oliveira and $\mathrm{Ni}^{21}$ \\
STR & 0.098 & & 7.84 & Vasconcelos et al. \\
ALR & 0.095 & & 8.3 & Vasconcelos et al. \\
BC & 0.00345 & & 0.37 & Deckwer et al. \\
& 0.066 & & 22 & Vasconcelos et al. ${ }^{30}$ \\
VBC & 0.02 & & 4 & Ellenberger and Krushna \\
\end{tabular}

${ }^{a}$ Abbreviations: OMT $=$ oscillatory mesotube; OFR $=$ oscillatory flow reactor; $\mathrm{SRT}=$ stirred-tank reactor; $\mathrm{BC}=$ bubble column; $\mathrm{ALR}=$ air-lift reactor; and $\mathrm{VBC}=$ vibrating bubble column.

$3.6-12.0 \%$, considering a partial $\mathrm{O}_{2}$ pressure, $y_{\mathrm{O}_{2}}=0.20948$, in atmospheric air. This also confirms the above assumption of constant gas flow rate; for the highest oxygen uptake rate, $v_{\mathrm{GS}}$ may have decreased by a maximum of $\sim 2.5 \%$.
The simplifications that were made when deriving the differential eqs 4-8 for oxygen mass transfer have an insignificant impact on the $k_{\mathrm{L}} a$ values, as shown in Figure 8. Actually, the simplifications having a higher impact on the $k_{\mathrm{L}} a$ values estimated for the OMT would have been related to neglecting both the liquid dispersion and the decrease in the partial pressure of oxygen in the gas phase. These two assumptions are quite common in studies for conventional gas-liquid contacting reactor systems. To measure the impact of different simplifications on the oxygen mass transport model in the OMT, $k_{\mathrm{L}} a$ values were estimated for decreasing levels of simplifications (A-D, respectively) and represented in Figure 8. For models $\mathrm{A}$ and $\mathrm{B}$, the diffusive flow term in eq 4 was neglected, while $\partial \bar{o}_{\mathrm{G}} / \partial l$ was considered null in eq 7 for models $\mathrm{A}$ and $\mathrm{C}$. The transport model described in the Experimental Apparatus and Procedures section corresponds to model D (or "full model"). The simplification of the liquid phase behaving as a plug flow rather than an axially dispersed flow (models A and B) would lead to an underestimation of $k_{\mathrm{L}} a$ values in the order of $50-60 \%$, while the effective decrease in the partial pressure of oxygen in the gas phase would represent an impact of 30-40\% when not taken into account. Models $\mathrm{A}-\mathrm{C}$ also showed a general tendency to a plateau for high values of $x$-axis by overestimating the driving force for the same value of $x_{\mathrm{O}_{2}}{ }^{\text {out }}$, associated with neglecting $D_{\mathrm{L}}$ and $\bar{o}_{\mathrm{L}}^{*}(z)$.

Figure 8 also demonstrates the importance of considering the axial dispersion in the liquid phase. The backflow generated by the axial, reciprocate movement of the fluid results to some extent in a controlled axial dispersion of oxygen through the length of the OMT, thus decreasing the local "driving force" for oxygen mass transfer in every $z$ point of the tube. The gas dynamics also have a strong effect in this work due to the low value of $v_{\mathrm{GS}}$ herein used, corresponding to a small ratio $Q_{\mathrm{G}} /$ $\left(Q_{\mathrm{G}}+Q_{\mathrm{L}}\right)$ and, consequently, a significant decrease in the partial pressure of oxygen (up to $\sim 12 \%$ ).

4.3. Sensibility Analysis of $\boldsymbol{k}_{\mathrm{L}} \boldsymbol{a}$. The impact of experimental errors on the estimated values of $k_{\mathrm{L}} a$ is herein discussed in relation to DO concentration and gas holdup values experimentally determined. The procedure involved measuring a DO concentration at one single axial point (i.e., at $z=1$ ) and adding it to the boundary condition for the gas at the inlet $(z=0)$. Thus, the estimated $k_{\mathrm{L}} a$ values are likely to be very sensitive to small deviations in $x_{\mathrm{O}_{2}}$ out. 

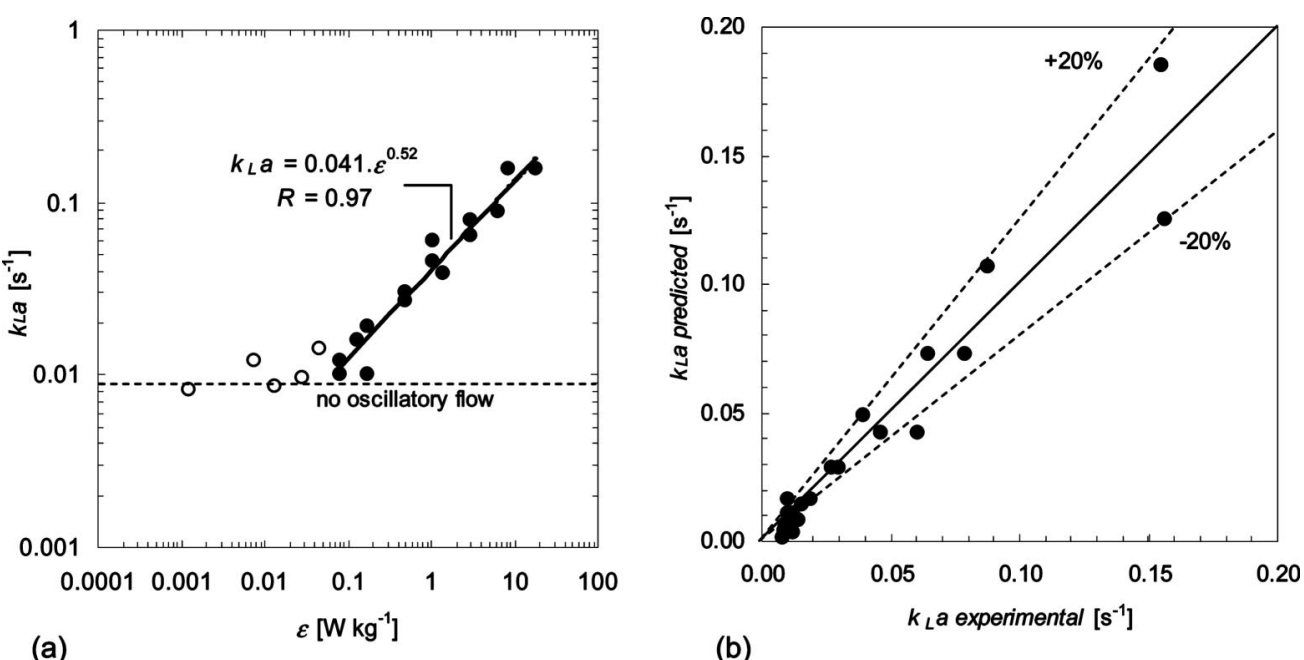

Figure 11. Correlation of $k_{\mathrm{L}} a$ with the cycle-average "turbulent" kinetic energy dissipation $(\bar{\varepsilon})$ in the OMT. (a) $\log -\log$ plot of $k_{\mathrm{L}} a$ versus $\bar{\varepsilon}$; the dots with white background represent values not considered in the correlation and obtained at $R e_{\mathrm{o}}<200$. (b) Parity plot comparing the predicted $k_{\mathrm{L}} a$ values with the experimental $k_{\mathrm{L}} a$ using eq 10 , line of parity (-), and (- -) represents $20 \%$ either side of parity.

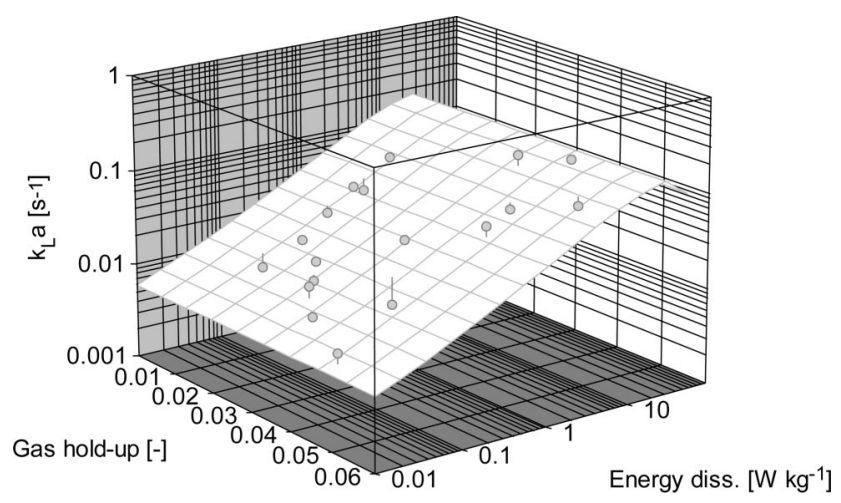

Figure 12. 3-D plot of $k_{\mathrm{L}} a$ versus $\varepsilon_{\mathrm{G}}$ and $\bar{\varepsilon}$.

The maximum standard deviation obtained for $x_{\mathrm{O}_{2}}{ }^{\text {out }}$ at the different combinations of $f$ and $x_{0}$ was $3.5 \%$ (at $20 \mathrm{~s}^{-1}$ and 3 $\mathrm{mm}$ ), and the very low holdups observed for certain fluid oscillation conditions (in the range of $1 \%$ ) pulled the inaccuracy in $\varepsilon_{\mathrm{G}}$ up to $\pm 25 \%$. Figure 9 a summarizes the impact of small deviations in DO on the estimated value of $k_{\mathrm{L}} a$ for three combinations of $f$ and $x_{0}$ and shows that the maximum deviation in $k_{\mathrm{L}} a$ is basically insignificant $(<1.3 \%)$, except for the two highest combinations of $f$ and $x_{0}$ herein tested (i.e., $15 \mathrm{~s}^{-1}, 3$ $\mathrm{mm}$ and $20 \mathrm{~s}^{-1}, 3 \mathrm{~mm}$ ), where the error goes up to $\pm 30-40 \%$. This is a consequence of the highly backmixed behavior obtained with the OMT2 at these particular fluid oscillating conditions (as summarized in Table 2). The experimental errors in gas holdup would result in a maximum deviation of $k_{\mathrm{L}} a$ of $\pm 3 \%$, as shown in Figure 9b.

4.4. Comparison of the OMT with Further Gas-Liquid Contacting Systems. Deckwer et al. ${ }^{28}$ have modeled the $k_{\mathrm{L}} a$ for a simple bubble column as follows,

$$
k_{\mathrm{L}} a=b v_{\mathrm{SG}}^{n}
$$

where $n$ and $b$ are empirical constants. Hewgill et al., ${ }^{12}$ working with an OFR, yielded results of $n=1.01$ and $b=10.1 \mathrm{~m}^{-1}$, which is consistent with Deckwer's results. Extrapolating such results for the present case study and considering that Hewgill's work was performed with $v_{\mathrm{SG}}$ in the range of $0.42-2.4 \mathrm{~mm}$ $\mathrm{s}^{-1}$ (with its minimum value very close to the $v_{\mathrm{SG}}$ value herein used, i.e. $0.37 \mathrm{~mm} \mathrm{~s}^{-1}$ ), a value for $k_{\mathrm{L}} a=0.00345 \mathrm{~s}^{-1}$ is estimated using eq 18. In the absence of fluid oscillations, the
$k_{\mathrm{L}} a$ value presented for the OMT in Figure $5\left(0.009 \mathrm{~s}^{-1}\right)$ represents a $\sim 2.5$-fold improvement in comparison with the value predicted by eq 18 . When fluid oscillations are used at $f$ $=20 \mathrm{~s}^{-1}$ and $x_{0}=3 \mathrm{~mm}$, the $k_{\mathrm{L}} a$ value is increased by $\sim 17$ times, representing a $\sim 45$-fold enhancement in comparison with Deckwer's relation.

This improvement in $k_{\mathrm{L}} a$ is related to the scale and geometry of the tube's constrictions (resulting in higher $\varepsilon_{\mathrm{G}}$ values and, consequently, higher specific surface area, $a$ ) and to the high radial mixing rates causing an increased "turbulence" at the gas-liquid interface. Such enhancement in mass transfer in the liquid-side film was actually expected from our computational fluid dynamics (CFD) studies and experimental particle image velocimetry (PIV) measurements, where we observed high radial rates of flow exchange between the walls and the center of the OMT coupled with high velocity gradients throughout a complete oscillation cycle. ${ }^{1}$ These typical flow patterns are illustrated in Figure 10.

The $k_{\mathrm{L}} a$ enhancement achieved by the radial mixing in the OMT is much more significant than the $k_{\mathrm{L}} a$ improvement reported by Ellenberger and Krishna ${ }^{14}$ for a bubble column reactor wherein the liquid phase is subjected to axial vibrations. These authors have found that $k_{\mathrm{L}} a$ values are improved by about a factor of 2 due to vibration excitement. In terms of mass transfer coefficient per unit volume of bubbles, $k_{\mathrm{L}} a / \varepsilon$, it has represented an increase from about $0.32 \mathrm{~s}^{-1}$ to a maximum of $0.63 \mathrm{~s}^{-1}$ in the presence of a vibration frequency of $60 \mathrm{~s}^{-1}$ and amplitude of $0.5 \mathrm{~mm}$. When associating periodic constrictions with the axial fluid oscillations as featured in the OMT, the generated vortex rings and considerable radial mixing allow a more significant improvement of $k_{\mathrm{L}} a / \varepsilon$ from 0.25 to $0.8-6.16$ $\mathrm{s}^{-1}$, for the ranges of $f$ and $x_{0}$ herein tested. The maximum obtained value of $k_{\mathrm{L}} a / \varepsilon=6.16 \mathrm{~s}^{-1}$ is $\sim 10$ times higher than the maximum value reported by Ellenberger and Krishna ${ }^{14}$ through simple, axial vibrations in a plain bubble column. This means the increase in the value of $k_{\mathrm{L}}$ (liquid-side mass transfer coefficient) is more significant in the OMT, revealing more effective "turbulent" kinetic energy dissipation. Table 3 briefly compares the values of $k_{\mathrm{L}} a$ obtained with the OMT with those reported for conventional gas-liquid contacting designs, including the vibrating bubble column of Ellenberger and Krishna. ${ }^{14}$

4.5. Modeling of $k_{\mathrm{L}} \boldsymbol{a}$ in the OMT. The $k_{\mathrm{L}} a$ in the OMT can be reasonably predicted by considering the mixing intensity 
or the energy dissipation at each combination of $f$ and $x_{0}$. Zheng ${ }^{29}$ has shown from the analysis of the velocity vector maps built with 2-D PIV that the cycle-average "turbulent" kinetic energy dissipation, $\bar{\varepsilon}\left(\mathrm{W} \mathrm{kg}^{-1}\right)$, can be predicted for this specific geometry with the following equation:

$$
\bar{\varepsilon}=28.55 \frac{v^{3}}{d^{4}} R e_{\mathrm{o}}^{2.6}
$$

When plotting $\log \left(k_{\mathrm{L}} a\right)$ versus $\log (\bar{\varepsilon})$, this returns a linear trend line for experiments performed at $R e_{\mathrm{o}} \geq 200$ (below this value of $R e_{\mathrm{o}}$, the flow patterns are axisymmetric and virtually repeatable on every oscillation cycle). The obtained correlation is plotted in Figure 11a and can be represented by the following equation:

$$
k_{\mathrm{L}} a=0.041 \bar{\varepsilon}^{0.52}
$$

The correlation in eq 20 predicts values of $k_{\mathrm{L}} a$ within a $\pm 20 \%$ error, as shown in Figure 11b. A further 3-D plot of $k_{\mathrm{L}} a$ versus $\varepsilon_{\mathrm{G}}$ and $\bar{\varepsilon}$ (Figure 12) allowed the conclusion that the gas holdup plays a marginal effect on the overall enhancement of $k_{\mathrm{L}} a$ in comparison with the rate at which the mechanical energy is locally dissipated by "turbulence".

\section{Conclusions}

The experimental results herein presented for gas-liquid contacting in the OMT have shown a major effect of the intensity of oscillatory flow mixing on both $\varepsilon_{\mathrm{G}}$ and $k_{\mathrm{L}} a$. The $\varepsilon_{\mathrm{G}}$ values determined for a continuous airflow rate of $0.28 \mathrm{~mL}$ $\min ^{-1}$ and a constant liquid flow rate of $1.58 \mathrm{~mL} \mathrm{~min}^{-1}$ were in the range of $1-5 \%$, which is comparatively higher than those values reported for a $50 \mathrm{~mm}$ internal diameter OFR or a vibrating bubble column. The geometry of the OMT, in particular the narrow, smooth-periodic constrictions (with a reduction in the free cross section of $\sim 87 \%$ ), is a major parameter distinguishing the gas-phase dynamics in this scaleddown system from that observed in the conventional OFR (with a typical free cross section of $75 \%$ ).

The oxygen mass transport model developed for the continuous, heterogeneous gas-liquid flow in the OMT demonstrated the major importance of considering both the decrease in the partial pressure of oxygen in the gas phase and the backmixing in the liquid phase during the design of tubular reactors based on this new OMT geometry. The $k_{\mathrm{L}} a$ values calculated for the OMT were significantly higher than the values typically found in conventional gas-liquid systems, while being obtained using a much lower mean superficial gas velocity; $k_{\mathrm{L}} a$ values were improved by about a factor of 5 in comparison with an OFR operating at the same value of peak oscillatory velocity and using only about one-quarter of the air per unit of reactor volume. The maximum $k_{\mathrm{L}} a$ value obtained with the OMT $\left(\sim 0.16 \mathrm{~s}^{-1}\right)$ represents a $\sim 50 \%$ enhancement in relation to the best $k_{\mathrm{L}} a$ values reported for highly efficient, large-scale biological reactors (such as stirred-tank reactors, airlift reactors, or bubble columns, with $k_{\mathrm{L}} a$ values up to $\sim 0.1 \mathrm{~s}^{-1}$ ), while using (at least) a $95 \%$ lower superficial air velocity. It also represents a 4-fold improvement in comparison with the gas-liquid flow studies in OFR (with reported $k_{\mathrm{L}} a$ values up to $0.04 \mathrm{~s}^{-1}$ ) and about an 8-fold increase in comparison with a vibrating bubble column for values of $v_{\mathrm{SG}}$ in the same order of magnitude.

A plot of $k_{\mathrm{L}} a$ versus the cycle-average turbulent kinetic energy dissipation rate and the gas holdup has demonstrated the marginal effect of $\varepsilon_{\mathrm{G}}$ to the overall enhancement of $k_{\mathrm{L}} a$. Therefore, a plot of $\log \left(k_{\mathrm{L}} a\right)$ versus $\log (\bar{\varepsilon})$ has returned a linear relation that can be used to predict $k_{\mathrm{L}} a$ values in this specific geometry within a $\pm 20 \%$ error. The major factor distinguishing the $k_{\mathrm{L}} a$ enhancement in this tubular reactor's geometry is the extent of radial mixing causing an increased turbulence at the gas-liquid interface.

The present work is an important step toward the design of novel continuous, scaled-down platforms based on the OMT's geometry, with potential applications in gas-liquid and gas-liquid-solid contacting, namely, bioprocesses where mass transfer of a solute (e.g., oxygen) from a gas into a liquid phase is often the rate-controlling step. The application of fluid oscillations in this constricted OMT allows a superior control of $k_{\mathrm{L}} a$ values, leading to the application of novel scale-down reactors as bioprocess screening units.

\section{Acknowledgment}

N.R. thanks the Portuguese Foundation for Science and Technology (FCT) for financial support of his work (SFRH/ BD/6954/2001).

\section{Nomenclature}

$d=$ tube internal diameter $(\mathrm{m})$

$d_{\text {mean }}=$ mean internal tube diameter $(\mathrm{m})$

$D_{\mathrm{L}}=$ axial dispersion coefficient $\left(\mathrm{m}^{2} \mathrm{~s}^{-1}\right)$

$f=$ oscillation frequency $\left(\mathrm{s}^{-1}\right)$

$h=$ gas-liquid dispersion level (m)

$h_{0}=$ liquid level (m)

$I_{0}=$ fluorescence intensity in the absence of oxygen (counts)

$I=$ fluorescence intensity in the presence of oxygen (counts)

$k_{\mathrm{c}}^{\prime}=$ Henry's constant (atm L mol ${ }^{-1}$ )

$k_{\mathrm{L}} a=$ overall volumetric oxygen mass transfer coefficient $\left(\mathrm{s}^{-1}\right)$

$K_{\mathrm{SV}}=$ Stern - Volmer constant $\left(\mathrm{m}^{3} \mathrm{~mol}^{-1}\right)$

$l=$ axial distance $(\mathrm{m})$

$L=$ total tube length $(\mathrm{m})$

$L^{\prime}=$ distance between the gas sparger and the micro-optrode $(\mathrm{m})$

$o_{\mathrm{L}}=$ dissolved oxygen concentration in the liquid phase $\left(\mathrm{mol} \mathrm{m}^{-3}\right)$

$o_{\mathrm{G}}=$ oxygen concentration in the gas phase $\left(\mathrm{mol} \mathrm{m}^{-3}\right)$

$o^{*}=$ equilibrium oxygen concentration $\left(\mathrm{mol} \mathrm{m}{ }^{-3}\right)$

$P=$ pressure $(\mathrm{atm})$

$P_{\mathrm{a}}=$ axial dispersion number (dimensionless)

$Q=$ volumetric flow rate $\left(\mathrm{m}^{3} \mathrm{~s}^{-1}\right)$

$R=$ ideal gas constant $\left(\mathrm{L}\right.$ atm $\left.\mathrm{mol}^{-1} \mathrm{~K}^{-1}\right)$

$R e_{\mathrm{o}}=$ oscillatory Reynolds number (eq 1 )

$t=$ time (s)

$T=$ temperature $(\mathrm{K})$

$v_{\mathrm{L}}=$ mean superficial liquid velocity $\left(\mathrm{m} \mathrm{s}^{-1}\right)$

$v_{\mathrm{SG}}=$ mean superficial gas velocity $\left(\mathrm{m} \mathrm{s}^{-1}\right)$

$V=$ volume $\left(\mathrm{m}^{3}\right)$

$x_{0}=$ oscillation center-to-peak amplitude (m)

$x_{\mathrm{O}_{2}}{ }^{\text {out }}=$ oxygen saturation at the outlet of the OMT (dimensionless)

$y=$ modified mixing cup concentration of $\mathrm{O}_{2}\left(\mathrm{~mol} \mathrm{~m}^{-3}\right)$

$y_{\mathrm{O}_{2}}=$ oxygen mol fraction in the gas phase $\left(\mathrm{mol}_{\mathrm{O}_{2}} \mathrm{~mol}_{\mathrm{air}}{ }^{-1}\right)$

$z=$ dimensionless axial distance

Greek Characters

$\bar{\varepsilon}=$ cycle-average "turbulent" kinetic energy dissipation $\left(\mathrm{W} \mathrm{kg}^{-1}\right)$

$\varepsilon_{\mathrm{G}}=$ gas holdup

$\mu=$ fluid viscosity $\left(\mathrm{kg} \mathrm{m}^{-1} \mathrm{~s}^{-1}\right)$

$\rho=$ density of the fluid $\left(\mathrm{kg} \mathrm{m}^{-3}\right)$

$\tau_{\mathrm{b}}=$ mean residence time of bubbles (s)

\section{Literature Cited}

(1) Reis, N.; Harvey, A. P.; Vicente, A. A.; Teixeira, J. A.; Mackley, M. R. Fluid Mechanics and Design Aspects of a Novel Oscillatory Flow Meso-Reactor. Chem. Eng. Res. Des. 2005, 83 (A4), 357-371. 
(2) Reis, N.; Gonçalves, C. N.; Vicente, A. A.; Teixeira, J. A. Proofof-concept of a novel micro-bioreactor for fast development of industrial bioprocesses. Biotechnol. Bioeng. 2006, 95 (4), 744-753.

(3) Gogate, P. R.; Pandit, A. B. Survey of measurement techniques for gas-liquid mass transfer coefficient in bioreactors. Biochem. Eng. J. 1999, 4 (1), 7-15.

(4) Blakebrough, N.; Sambamurthy, K. Mass Transfer and Mixing Rates in Fermentation Vessels. Biotechnol. Bioeng. 1966, 8 (1), 25-42.

(5) Baird, M. H. I.; Garstang, J. H. Power Consumption and Gas Holdup in a Pulsed Column. Chem. Eng. Sci. 1967, 22 (12), 1663-1973.

(6) Baird, M. H. I.; Garstang, J. H. Gas Absorption in a Pulsed Bubble Column. Chem. Eng. Sci. 1972, 27 (4), 823-833.

(7) Linek, V.; Sinkule, J.; Benes, P. Critical-Assessment of Gassing-in Methods for Measuring $k_{\mathrm{L}} a$ in Fermenters. Biotechnol. Bioeng. 1991, 38 (4), 323-330.

(8) Linek, V.; Sinkule, J.; Benes, P. Critical-Assessment of the Dynamic Double-Response Method for Measuring $k_{\mathrm{L}} a$-Experimental Elimination of Dispersion Effects. Chem. Eng. Sci. 1992, 47 (15-16), 3885-3894.

(9) Serieys, M.; Goma, G.; Durand, G. Design and Oxygen-Transfer Potential of a Pulsed Continuous Tubular Fermentor. Biotechnol. Bioeng. 1978, 20 (9), 1393-1406.

(10) Mackley, M. R. Process Innovation Using Oscillatory Flow within Baffled Tubes. Chem. Eng. Res. Des. 1991, 69 (3), 197-199.

(11) Bellhouse, B. J.; Bellhous, F. H.; Curl, C. M.; Macmilla, T. I.; Gunning, A. J.; Spratt, E. H.; Macmurra, S. B.; Nelems, J. M. HighEfficiency Membrane Oxygenator and Pulsatile Pumping System, and Its Application to Animal Trials. Trans. Am. Soc. Artif. Int. Organs 1973, 19, $72-79$.

(12) Hewgill, M. R.; Mackley, M. R.; Pandit, A. B.; Pannu, S. S. Enhancement of Gas-Liquid Mass-Transfer Using Oscillatory Flow in a Baffled Tube. Chem. Eng. Sci. 1993, 48 (4), 799-809.

(13) Ni, X.; Gao, S.; Cumming, R. H.; Pritchard, D. W. A ComparativeStudy of Mass-Transfer in Yeast for a Batch Pulsed Baffled Bioreactor and a Stirred-Tank Fermenter. Chem. Eng. Sci. 1995, 50 (13), 2127-2136.

(14) Ellenberger, J.; Krishna, R. Shaken, not stirred, bubble column reactors: Enhancement of mass transfer by vibration excitement. Chem. Eng. Sci. 2003, 58 (3-6), 705-710.

(15) Linek, V.; Vacek, V.; Benes, P. A Critical-Review and ExperimentalVerification of the Correct Use of the Dynamic Method for the Determination of Oxygen-Transfer in Aerated Agitated Vessels to Water, ElectrolyteSolutions and Viscous-Liquids. Chem. Eng. J. Biochem. Eng. J. 1987, 34 (1), 11-34.

(16) Ni, X. W.; Gao, S. W.; Pritchard, D. W. Study of Mass-Transfer in Yeast in a Pulsed Baffled Bioreactor. Biotechnol. Bioeng. 1995, 45 (2), $165-175$.
(17) $\mathrm{Ni}, \mathrm{X}$.; Gao, S. Scale-up correlation for mass transfer coefficients in pulsed baffled reactors. Chem. Eng. J. 1996, 63 (3), 157-166.

(18) van't Riet, K. Review of Measuring Methods and Results in Nonviscous Gas-Liquid Mass-Transfer in Stirred Vessels. Ind. Eng. Chem. Process Des. Dev. 1979, 18 (3), 357-364.

(19) Gouin, J. F.; Baros, F.; Birot, D.; Andre, J. C. A fibre-optic oxygen sensor for oceanography. Sens. Actuators, B 1997, 39 (1-3), 401-406.

(20) Oliveira, M. S. N.; Ni, X. Gas hold-up and bubble diameters in a gassed oscillatory baffled column. Chem. Eng. Sci. 2001, 56 (21-22), 61436148

(21) Oliveira, M. S. N.; Ni, X. W. Effect of hydrodynamics on mass transfer in a gas-liquid oscillatory baffled column. Chem. Eng. J. 2004, 99 (1), 59-68.

(22) Wang, W.; Reimers, C. E.; Wainright, S. C.; Shahriari, M.; Morris, M. J. Applying fiber-optic sensors for monitoring dissolved oxygen. Sea Technol. 1999, 40 (3), 69-74.

(23) Reis, N.; Vicente, A. A.; Teixeira, J. A.; Mackley, M. R. Residence times and mixing of a novel continuous oscillatory flow screening reactor. Chem. Eng. Sci. 2004, 59 (22-23), 4967-4974.

(24) Hanhart, J.; Kramers, H.; Westerterp, K. R. The residence time distribution of the gas in an agitated gas-liquid contactor. Chem. Eng. Sci. 1963, 18 (8), 503-509.

(25) Baird, M. H. I.; Stonestreet, P. Energy-Dissipation in Oscillatory Flow within a Baffled Tube. Chem. Eng. Res. Des. 1995, 73 (A5), 503511.

(26) Renka, R. Algorithm 751: TRIPACK: A Constrained TwoDimensional Delaunay Triangulation Package. ACM Trans. Math. Software 1996, 22 (1), 1-8.

(27) Jealous, A. C.; Johnson, H. F. Power Requirements for Pulse Generation in Pulse Columns. Ind. Eng. Chem. 1955, 47 (6), 1168-1169.

(28) Deckwer, W. D.; Burckhar, R.; Zoll, G. Mixing and Mass-Transfer in Tall Bubble Columns. Chem. Eng. Sci. 1974, 29 (11), 2177-2188.

(29) Zheng, M. Development of a continuous oscillatory flow meso reactor. Ph.D. Thesis, University of Cambridge, Cambridge, U.K., 2008.

(30) Vasconcelos, J. M. T.; Rodrigues, J. M. L.; Orvalho, S. C. P.; Alves, S. S.; Mendes, R. L.; Reis, A. Effect of contaminants on mass transfer coefficients in bubble column and airlift contactors. Chem. Eng. Sci. 2003, 58 (8), 1431-1440.
Received for review January 29, 2008 Revised manuscript received June 20, 2008 Accepted June 24, 2008 